University of Nebraska - Lincoln

DigitalCommons@University of Nebraska - Lincoln

2011

\title{
Characterizing 3D vegetation structure from space: Mission requirements
}

\author{
Forrest G. Hall \\ University of Maryland Baltimore County \\ Kathleen Bergen \\ University of Michigan \\ James B. Blair \\ NASA Goddard Space Flight Center \\ Ralph Dubayah \\ University of Maryland University College \\ Richard Houghton \\ Woods Hole Research Center \\ See next page for additional authors
}

Follow this and additional works at: https://digitalcommons.unl.edu/nasapub

Part of the Physical Sciences and Mathematics Commons

Hall, Forrest G.; Bergen, Kathleen; Blair, James B.; Dubayah, Ralph; Houghton, Richard; Hurtt, George; Kellndorfer, Josef; Lefsky, Michael; Ranson, Jon; Saatchi, Sassan; Shugart, H.H.; and Wickland, Diane, "Characterizing 3D vegetation structure from space: Mission requirements" (2011). NASA Publications. 60 .

https://digitalcommons.unl.edu/nasapub/60

This Article is brought to you for free and open access by the National Aeronautics and Space Administration at DigitalCommons@University of Nebraska - Lincoln. It has been accepted for inclusion in NASA Publications by an authorized administrator of DigitalCommons@University of Nebraska - Lincoln. 


\section{Authors}

Forrest G. Hall, Kathleen Bergen, James B. Blair, Ralph Dubayah, Richard Houghton, George Hurtt, Josef Kellndorfer, Michael Lefsky, Jon Ranson, Sassan Saatchi, H.H. Shugart, and Diane Wickland 


\title{
Characterizing 3D vegetation structure from space: Mission requirements
}

\author{
Forrest G. Hall ${ }^{\mathrm{a}, *}$, Kathleen Bergen ${ }^{\mathrm{b}}$, James B. Blair ${ }^{\mathrm{c}}$, Ralph Dubayah ${ }^{\mathrm{d}}$, Richard Houghton ${ }^{\mathrm{f}}$, George Hurtt ${ }^{\mathrm{g}}$, \\ Josef Kellndorfer $^{\text {f }}$, Michael Lefsky ${ }^{j}$, Jon Ranson ${ }^{c}$, Sasan Saatchi ${ }^{\text {h}}$, H.H. Shugart ${ }^{i}$, Diane Wickland ${ }^{\mathrm{e}}$ \\ a University of Maryland Baltimore County, Joint Center for Earth Systems Technology, United States \\ ${ }^{\mathrm{b}}$ University of Michigan, School of Natural Resources and Environment, United States \\ c NASA Goddard Space Flight Center, United States \\ ${ }^{\mathrm{d}}$ University of Maryland University College, Department of Geography, United States \\ e NASA Headquarters, United States \\ ${ }^{f}$ Woods Hole Research Center, United States \\ ${ }^{g}$ University of New Hampshire, Institute for the Study of Earth, Oceans and Space, United States \\ h Jet Propulsion Laboratory, United States \\ i University of Virginia, Charlottesville, Department of Environmental Sciences, United States \\ j Colorado State University, Department of Forestry, United States
}

\section{A R T I C L E I N F O}

\section{Article history:}

Received 15 January 2009

Received in revised form 9 December 2010

Accepted 7 January 2011

\section{Keywords:}

Biomass

$3 \mathrm{D}$ vegetation tructure

Carbon cycle

Remote sensing

Radar

Lidar

DESDynI

\begin{abstract}
A B S T R A C T
Human and natural forces are rapidly modifying the global distribution and structure of terrestrial ecosystems on which all of life depends, altering the global carbon cycle, affecting our climate now and for the foreseeable future, causing steep reductions in species diversity, and endangering Earth's sustainability.

To understand changes and trends in terrestrial ecosystems and their functioning as carbon sources and sinks, and to characterize the impact of their changes on climate, habitat and biodiversity, new space assets are urgently needed to produce high spatial resolution global maps of the three-dimensional (3D) structure of vegetation, its biomass above ground, the carbon stored within and the implications for atmospheric green house gas concentrations and climate. These needs were articulated in a 2007 National Research Council (NRC) report (NRC, 2007) recommending a new satellite mission, DESDynI, carrying an L-band Polarized Synthetic Aperture Radar (Pol-SAR) and a multi-beam lidar (Light RAnging And Detection) operating at $1064 \mathrm{~nm}$. The objectives of this paper are to articulate the importance of these new, multi-year, 3D vegetation structure and biomass measurements, to briefly review the feasibility of radar and lidar remote sensing technology to meet these requirements, to define the data products and measurement requirements, and to consider implications of mission durations. The paper addresses these objectives by synthesizing research results and other input from a broad community of terrestrial ecology, carbon cycle, and remote sensing scientists and working groups. We conclude that:
\end{abstract}

(1) Current global biomass and 3-D vegetation structure information is unsuitable for both science and management and policy. The only existing global datasets of biomass are approximations based on combining land cover type and representative carbon values, instead of measurements of actual biomass. Current measurement attempts based on radar and multispectral data have low explanatory power outside low biomass areas. There is no current capability for repeatable disturbance and regrowth estimates.

(2) The science and policy needs for information on vegetation 3D structure can be successfully addressed by a mission capable of producing (i) a first global inventory of forest biomass with a spatial resolution $1 \mathrm{~km}$ or finer and unprecedented accuracy (ii) annual global disturbance maps at a spatial resolution of 1 ha with subsequent biomass accumulation rates at resolutions of $1 \mathrm{~km}$ or finer, and (iii) transects of vertical and horizontal forest structure with $30 \mathrm{~m}$ along-transect measurements globally at $25 \mathrm{~m}$ spatial resolution, essential for habitat characterization.

We also show from the literature that lidar profile samples together with wall-to-wall L-band quad-pol-SAR imagery and ecosystem dynamics models can work together to satisfy these vegetation 3D structure and biomass measurement requirements. Finally we argue that the technology readiness levels of combined pol-SAR and lidar instruments are adequate for space flight. Remaining to be worked out, are the particulars of a lidar/pol-SAR mission design that is feasible and at a minimum satisfies the information and measurement requirement articulated herein.

(c) 2011 Published by Elsevier Inc.

\footnotetext{
* Corresponding author. Tel.: +1 301614 6659; fax: +1 3016146695

E-mail address: Forrest.G.Hall@nasa.gov (F.G. Hall).
} 


\section{Introduction}

The structure and extent of global forest cover are changing rapidly, altering the major terrestrial sink and source of atmospheric carbon dioxide $\left(\mathrm{CO}_{2}\right)$. As forests grow and increase their biomass, $\mathrm{CO}_{2}$ is absorbed. Terrestrial ecosystems have the capability to absorb nearly a third of the current carbon (C) emissions from fossil fuel combustion, slowing atmospheric green house gas accumulation, a service with enormous economic value (Stern Report, 2008). While forest clearing from human-driven land use change can increase albedo reducing warming, land-use change also releases carbon as $\mathrm{CO}_{2}$ accelerating warming. Land-use change also results in habitat loss, impacting biodiversity. Regrowth following disturbance can restore habitat to some extent, but the success of this depends on sufficient conservation management information on species habitat requirements and their relationships to vegetation three-dimensional (3D) structure, i.e. vegetation vertical structure and biomass plus horizontal landscape patch structure (Bergen et al., 2009; Martinuzzi et al., 2009).

The amounts of $C$ stored within and released to the atmosphere through land-use change and regrowth are poorly known, creating large uncertainties in the global carbon budget and future climate. The uncertainty is directly related to very limited knowledge of the $3 \mathrm{D}$ structure of global forests, which is required to accurately estimate biomass and biomass change, carbon storage and release, hence climate change, habitat and biodiversity. Better information is needed if we are to understand our vulnerability to climate change, and the vulnerability of life to not only climate change, but to changes in their habitat as reflected in changes to the structure and extent of forests.

The objectives of this paper are to articulate the importance of acquiring these new, multi-year, 3D vegetation structure and biomass measurements, to briefly review the potential of polarized synthetic aperture radar (Pol-SAR) and lidar remote sensing technology to obtain these measurements and to define the precision, extent, temporal and the finest spatial resolution desired and the coarsest spatial resolution required. We will also discuss the nature and duration of the required satellite mission needed to obtain the desired and required data products.

In Section 1.1 we review in greater detail the essential roles that the Earth's forests play in the global carbon cycle, hence future climate. We also further examine the important role that forests play in the sustainability of habitat and biodiversity. We then summarize the open science issues that must be addressed to improve our understanding and quantify these critical roles. In section 1.2 we review the new information required to address these science issues. In Section 1.3 we define an ensemble of new measurements of forest 3D structure needed to provide this information. In Section 2 we assess the feasibility of combined satellite lidar and pol-SAR measurements of global vegetation structure, biomass and biomass change to obtain these essential measurements. We devote Section 3 to a detailed quantification of the measurement requirements that represent a synthesis of numerous discussions among the co-authors and others, beginning with a March 2008 NASA-sponsored workshop at the University of Virginia, Charlottesville attended by more than 100 scientists from relevant disciplines, followed up by regular teleconferences since then. Section 4 summarizes the conclusions of this study.

\subsection{Science and policy issues needing resolution}

In this section we examine the importance of acquiring new scientific information and related measurements to quantify and understand the impacts on climate (Section 1.1.1) and habitat and biodiversity (Section 1.1.2) resulting from the rapid alteration of the extent and structure of terrestrial ecosystems. In Section 1.1.3 we discuss how the provision of this missing information could provide necessary but currently unavailable data to inform significant climate policy decisions.

\subsubsection{Biomass, the carbon cycle and climate}

Terrestrial ecosystems play a huge role in current and future climate. Analyses show (Canadell et al., 2007, Denman et al. 2007a, 2007b, and Friedlingstein et al., 2010, Le Quéré et al., 2009 and see Fig. 1) that on average terrestrial ecosystems are absorbing more than one-third of the fossil fuel emissions, or $\sim 2.7$ of 7.7 Peta $\left(10^{15}\right)$ grams carbon per year $\left(\mathrm{PgC} \mathrm{yr}^{-1}\right)$. Estimates of the fossil fuel, atmospheric storage, land use change and ocean uptake components of the global carbon budget are based on various data sources, and are uncertain to varying degrees (Fig. 1); so uncertain that we cannot "close" the global carbon budget. The magnitude and uncertainty of the "missing" terrestrial sink $(2.7 \pm 1$ $\mathrm{PgC} \mathrm{yr}^{-1}$ ) are not based on direct measures, hence its location and cause is unknown. Rather its magnitude and uncertainty is computed as the difference among the various carbon budget components and their uncertainties (see the equation in Fig. 1). The estimated magnitude is large, and its economic importance is huge, but we cannot say much about it other than that it is terrestrial in nature, most likely located in forested ecosystems. But exactly where it is located, or how long it will continue we cannot say without more information, thus it motivates the urgent need for a global vegetation 3D structure and biomass mission.

Why is this important? From an economic perspective, net uptake of $\mathrm{CO}_{2}$ by terrestrial ecosystems provides an estimated societal benefit of $\sim \$ 3$ Trillion through mid-century. How? Without it, atmospheric $\mathrm{CO}_{2}$ concentrations would increase over the next 40 yrs to 2050 by more than $100 \mathrm{PgC}$. The additional climate warming and subsequent thinning of the Earth's ice sheets and associated sea level rise, as well as other climate impacts to society are estimated by the Stern Report (2008) to be at a minimum, $\$ 30$ for each metric ton of carbon or $\$ 30$ billion/PgC of emissions, a total of $\sim \$ 3$ trillion social costs. Will this huge net economic benefit continue in the future? Unfortunately, the global carbon budget in Fig. 1 is too uncertain to predict the future of the terrestrial sink strength or the atmospheric $\mathrm{CO}_{2}$ trajectories with much confidence. Recent evidence suggests that this terrestrial sink strength may have actually decreased over the last $48 \mathrm{yrs}$, (Canadell et al., 2007).

One of the most uncertain of the "known" terms in Fig. 1 is the loss of carbon to the atmosphere from land use change $\left(1.4{\mathrm{PgC} \mathrm{yr}^{-1}}^{-1}\right.$. At least half of this uncertainty results from uncertain estimates of standing biomass (Houghton, 2005). The major source of that uncertainty is how much biomass is lost when tropical forests are converted to other land uses. Recent calculations (Houghton, 2005) estimate a net positive tropical carbon flux to the atmosphere to be somewhere between 0.84 and $2.15 \mathrm{PgC} \mathrm{yr}^{-1}$.

In addition to cycling carbon to and from the atmosphere, forests also play a major role in climate change by affecting the exchange of solar energy and water between the atmosphere and the Earth's surface; increasing forest cover reduces albedo, increasing radiative climate forcing, but increases evapotranspiration and carbon uptake by forests, decreasing climate forcing overall (Bounoua et al., 2000, 2010). However, forest extent and structure are both being rapidly altered by land use change (Fig. 2) and without improved information on these factors, impacts on future climate are uncertain. It is estimated from ground surveys and remote sensing that from 1990 to 2000 deforestation in the tropics exceeded 12 million ha/yr (Millennium Ecosystem Assessment Synthesis Report, 2005). Forest degradation was offset to some extent by a smaller increase of 3 million ha/ $\mathrm{yr}$ in the area of temperate forest. We need improved information as to how these changes are affecting the Earth's carbon cycle, its radiation budget, hence climate, or its biodiversity, now and in the future. It is essential, both from a climate and ecological perspective to develop better information (Houghton and Goetz, 2008).

\subsubsection{Forest structure, habitat and biodiversity}

From an ecological perspective the rapid change in vegetation 3D forest structure worldwide, including habitat fragmentation, species 


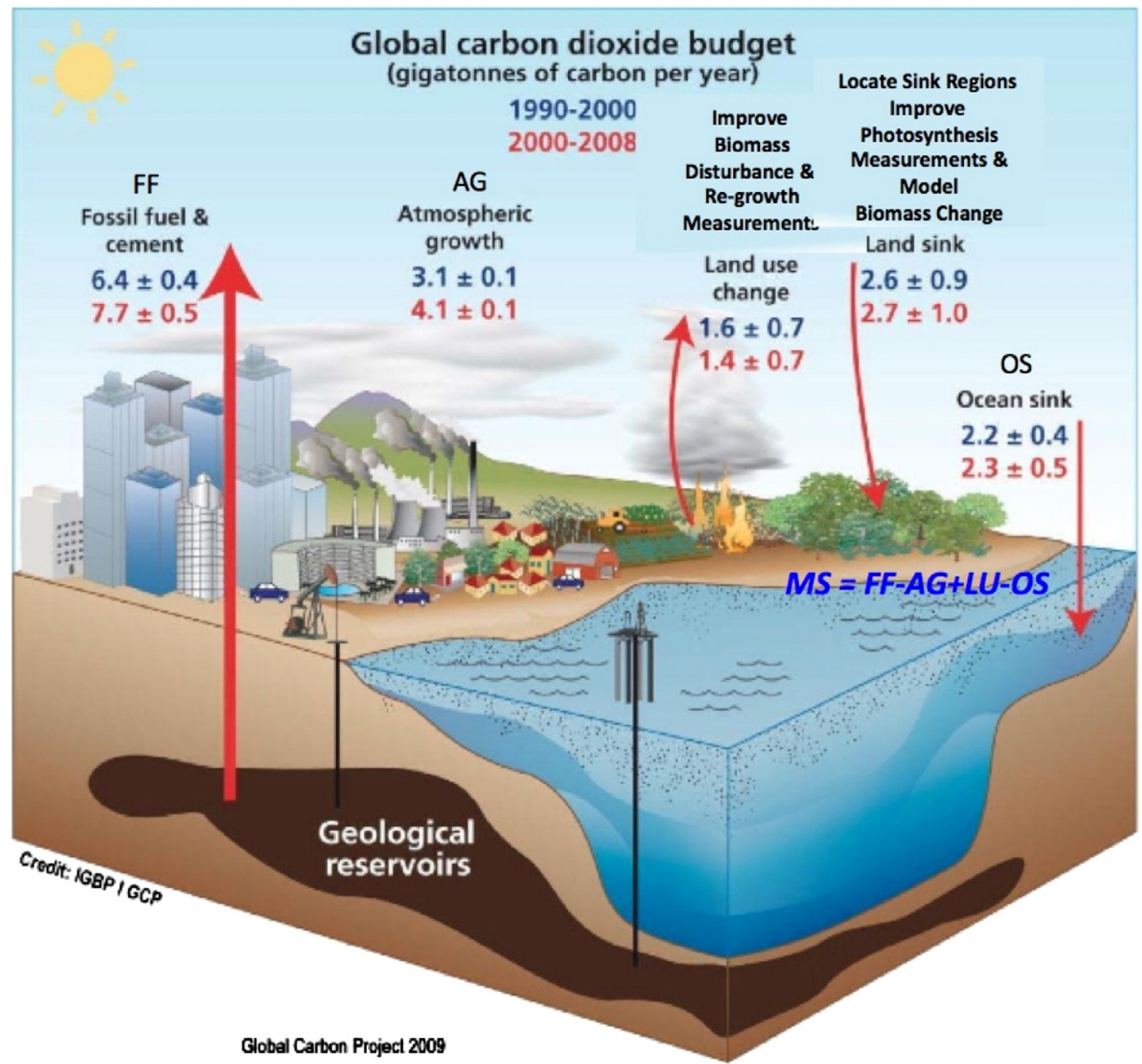

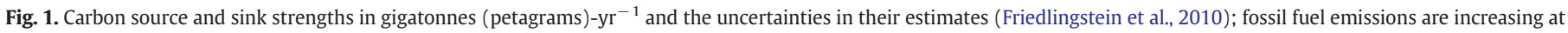

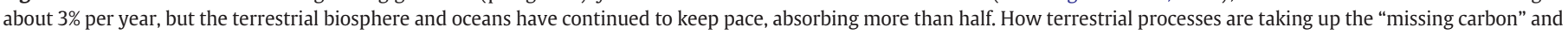
how long they can continue aretwo of the critical and challenging questions for understanding future climate change.

extinctions and spread of invasive species are already having undesirable consequences for biodiversity (Butchart et al., 2010). Known species may be at risk of extinction. Invasive species may gain footholds. Undiscovered species may be eliminated before they are even recorded by taxonomists. One study estimates that globally, the terrestrial species population index decreased by 31\% from 1970 to 2006; another study by about 30\% from 1970 to 2003 (World Wildlife Fund, 2006). These declines can be partially attributed to loss and fragmentation of vegetated habitat. In tropical biomes species abundance decreased over the past 33 yrs by 55\%. Almost threequarters of Earth's species occur in only 12 countries: Australia, Brazil, China, Columbia, Ecuador, India, Indonesia, Madagascar, Mexico, Peru, and Zaire. These are the same areas that are undergoing unprecedented land use change resulting in significant alteration in vegetation 3D structure and biomass. Unfortunately, there is a paucity of information on the rate, extent and location of these structural alterations, and the resulting changes in forest biomass. Butchart et al., 2010 notes that "...Global trends for habitat fragmentation are unavailable...".

\subsubsection{Policy implications}

In addition to producing major advances in our knowledge of how forests are changing and how these changes are affecting the global carbon cycle, climate and biodiversity, better monitoring from space can play a major role supplying objective information to support international carbon emission reduction initiatives, now and in the future. Many examples could be cited. A good example would be the "Reduced Emissions from Deforestation and Degradation" (REDDplus) initiative from the recent Copenhagen summit, proposed as a means to cut greenhouse gas emissions associated with forest clearing by the inclusion of "avoided deforestation" in carbon market mechanisms; in short, payments to countries in return for their preservation of existing forests. REDD-Plus would also provide monetary incentives for developing countries to reduce greenhouse emissions beyond deforestation and forest degradation through sustainable forest management, afforestation and reforestation. (Angelsen et al., 2009; DeFries et al., 2007; Rosenqvist et al., 2003; UNFCCC LCA Agreement on REDD, 2009).

Improved 3D vegetation structure data will also provide urgently needed information for other important applications in our changing climate, for example, forest fire management. As the wild/urban interface between development and forest increases, the potential for catastrophic fires is greatly enhanced. USDA Forest Service fire spread models require structural inputs such as canopy height, canopy biomass and moisture content, vertical biomass profiles, and canopy base height (Weise \& Biging, 1997). The destructive fires of 2007 in 


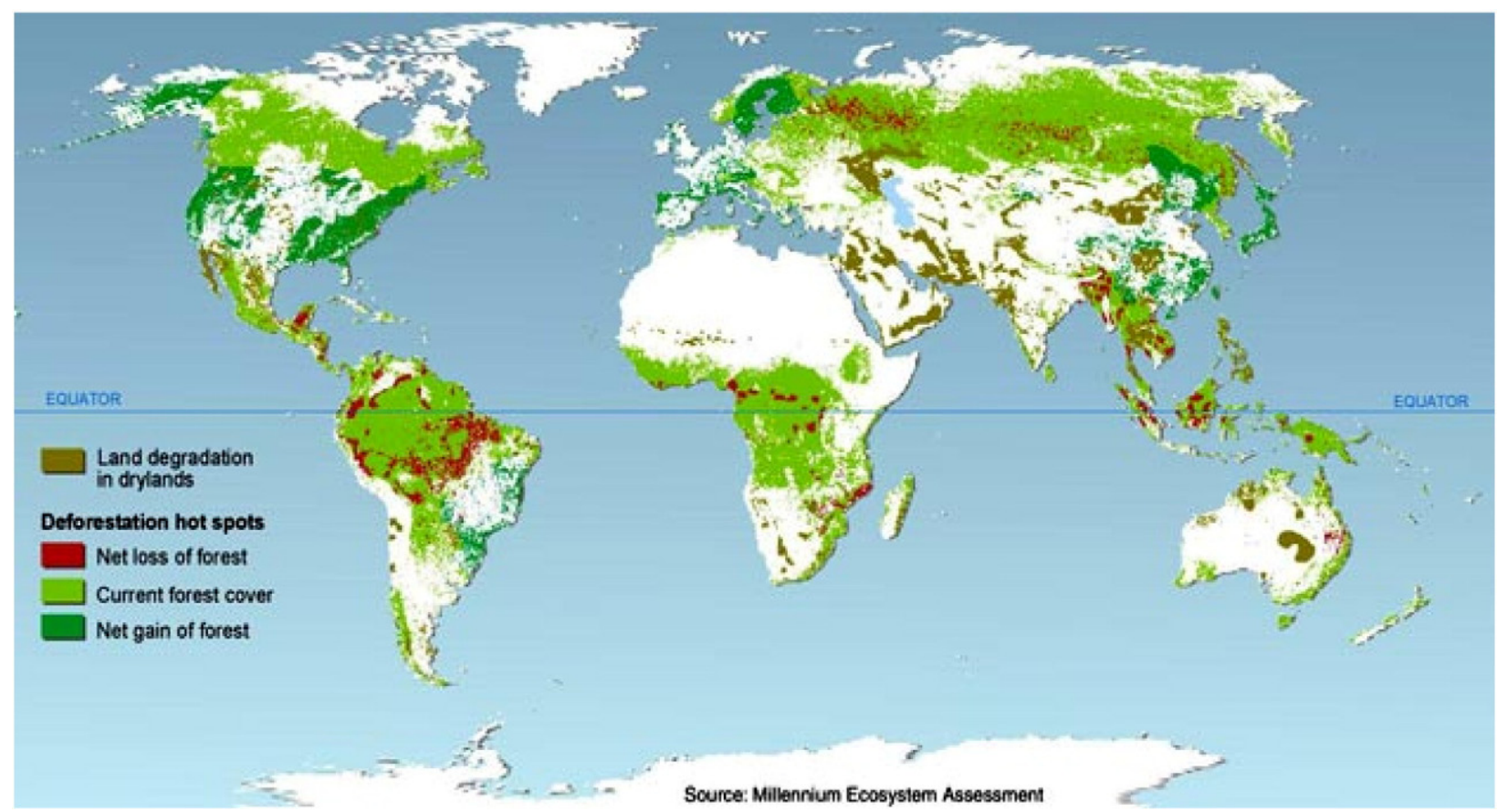

Fig. 2. Global changes in forested area from the Millennium Ecosystem Assessment Synthesis Report (2005).

Southern California highlight the need for information about the distribution of fire fuel loads at landscape to regional scales to improve fire spread models for forest fire prediction and mitigation.

Improved capability to predict the consequences of changes in drivers for biodiversity, ecosystem functioning, and ecosystem services, together with improved measures of biodiversity, would aid decision-making at a number of levels (Millenium Ecosystem Assessment, 2005). Strategic decisions are already being made as to what biodiversity will be maintained on the global landscape (Brooks et al., 2006; Butchart et al., 2010; Olson and Dinerstein 2002). At the more local level, management organizations are seeking to benefit from access to information on vegetation structure in assessing biodiversity and/or habitat. For example, the U.S. Geological Survey GAP program regularly maps habitat of species in each U.S. State based on Landsat-derived "habitat" (vegetation type) maps combined with models of wildlife habitat suitability requirements. Because these data and models frequently over-predict habitat in ways that could be remedied by introducing vegetation 3D structure, GAP programs are investigating which common habitat structure variables could be retrieved from Lidar instruments and used to improve the mapping of habitat (Martinuzzi et al., 2009).

\subsection{Information needed to address science issues}

An entire class of environmental problems cannot be addressed with the information available from current forest structure and biomass survey methods. While existing satellite remote sensing can provide spatially resolved global maps of the areal extent of forests and deforestation (Tucker \& Townshend, 2000), the lack of spatially resolved information on forest structure and biomass severely limits knowledge of biomass and biomass change and subsequent carbon exchange with the atmosphere (Frolking et al., 2009; Houghton, 2005) as well as impacts on habitat and biodiversity (Bergen et al., 2005). In Section 1.2.1 information needed to resolve uncertainties in the global carbon budget will be reviewed, and in Section 1.2.2 the information needed to map vegetation variables related to habitat and biodiversity. In Section 1.3 the general types of measurements required (in situ and remote sensing) to obtain this information will be described. In Section 3 we will quantify the measurement error, spatial and temporal characteristics.

\subsubsection{Information needs for the global carbon budget}

The total amount of carbon contained in the forest's biomass is not known to even one significant Figure. Estimates range from 385 to 650 PgC (FAO, 2006; Goodale et al., 2002; Houghton et al., 2009; Saugier et al., 2001). Satellite monitoring of the ongoing rapid degradation of the Earth's terrestrial forest cover and its mass change can reduce the magnitude of this huge uncertainty.

What terrestrial carbon information is required to reduce these uncertainties? For forested and savanna/wooded ecosystems (Fig. 3), it is the live and non-living carbon contained within the layer of organic biomass of above ground trees and understory and below ground roots. The biomass of woody plants is the most important component of terrestrial organic carbon. Forests are estimated to hold 70-90\% of terrestrial above- and belowground biomass (Houghton, 2008). Within forests, above ground biomass (AGBM) accounts for $70-90 \%$ of the total, most of it in trees (Cairns et al., 1997).

Aboveground or standing forest biomass as used herein means the total dry weight of wood above ground. Biomass density is the biomass per unit area, but we will use the term biomass and biomass density interchangeably. We will use units of Megagrams per hectare $\mathrm{Mg} \mathrm{ha}^{-1}$ ( $1000 \mathrm{~kg} \mathrm{~m}^{-2}$ or 1 metric ton $\mathrm{m}^{-2}$ ) as our standard unit of biomass measure. Forest biomass is approximately $50 \%$ carbon. We will use Megagrams carbon per hectare $\mathrm{MgC} \mathrm{ha}{ }^{-1}$ when referring to carbon density, where $1 \mathrm{MgC} \mathrm{ha}^{-1}$ is equivalent to $2 \mathrm{Mg} \mathrm{ha}^{-1}$ biomass.

Changes in standing biomass dominate changes in net terrestrial carbon flux (Houghton, 2005). Belowground carbon stored in roots, rhizomes, and soil microbes contributes to a lesser extent. Soil organic matter (decomposed plant matter no longer identifiable as such) holds two to three times more carbon globally than biomass; but is usually not considered in short term forest/atmosphere carbon exchange, since much of the soil carbon is physically and chemically protected and not easily oxidized (Davidson \& Janssens, 2006). Wood products for construction, paper, etc., also gradually release carbon to the atmosphere as they oxidize. 


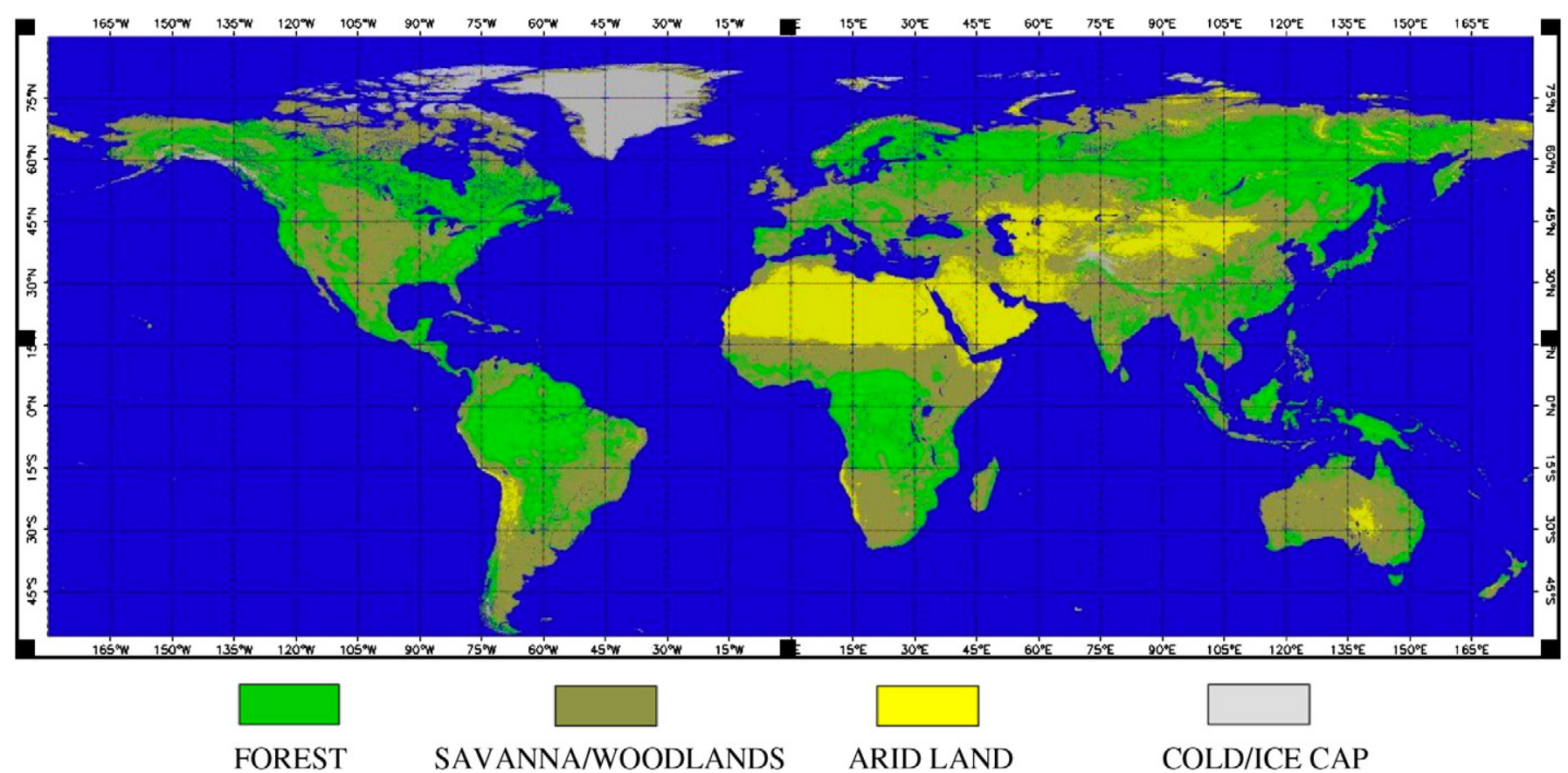

Fig. 3. Target locations for forest structure and biomass measurements including existing forest and savanna/woodlands.

It is necessary to obtain vegetation 3D structure and biomass and biomass change information regionally as well as globally. Estimates show that biomass ranges over two to three orders of magnitude between biomes, from more than $600 \mathrm{Mg} \mathrm{ha}^{-1}$ in some tropical forests and temperate rainforests of the Pacific Northwest in North America to less than $\mathrm{Mg} \mathrm{ha}^{-1}$ in treeless grasslands, croplands, and deserts.

Structure and biomass can vary as much within ecosystems as between them. The variability results in part from differences in disturbance modalities, physiognomy and recovery processes at the much fine scales of forest disturbance and regrowth.

Thus fine scale, spatially contiguous observations of biomass and 3D structure will be required to calibrate ecosystem dynamics and carbon models for prognosticating future trends in the strength of the land carbon sink and biodiversity as a function of current rates, modalities and locations of land use change.

\subsubsection{Information needs for habitat and biodiversity}

A number of quantitative and observable 3D forest structure characteristics are needed to characterize habitat (canopy cover, tree and canopy height, vertical structure, and tree volume) (MacArthur \& MacArthur, 1961; Anderson \& Shugart, 1974; Willson, 1974; Morgan \& Freedman, 1986). As described in Section 1.3 these same variables are also needed to estimate biomass. At landscape scales, the spatial heterogeneity of a vegetated region of interacting multi-dimensional vegetation communities and animal habitats influences how plant and animal biodiversity is distributed (Imhoff et al., 1997; Tews et al., 2004). A large diversity of tree size distributions can indicate a wide range of habitat for wildlife (Morgan \& Freedman, 1986) and thus stand variation in tree height and diameter is an important consideration in biodiversity conservation in forested landscapes. Edges provide habitat for many organisms and the amount, variety and structural characteristics of edges may be related positively to habitat. Likewise amount of edge may also be a significantly negative effect of forest fragmentation on other species (Matlack \& Litvaitis, 1999). Landscape pattern metrics (e.g. shape, size, contiguity, edge density, etc.) are now standard in wildlife habitat and corridor science management. Biomass is also a useful indirect indicator of age, as well as of density and successional stage, although vegetation structure factors more easily measured in the field than biomass are known to influence habitat selection and both plant and animal diversity (Hartung \& Brawn, 2005; Reinkensmeyer et al., 2007a, 2007b; Bergen et al., 2007).

The key biodiversity and habitat variables are needed at both the patch-level and landscape-level. While these 3D forest characteristics have been measured for forest stands using various in situ techniques, and have all been shown through various studies to be related to observed species diversity in geographically limited areas, such in situ measures are labor intensive, therefore severely limiting the scope of habitat and biodiversity studies. Availability of these measures at key biodiversity regional "hotspots" around the globe and over time would revolutionize our understanding of how forest 3D structure and its change over time is affecting the habitat and diversity of lifeforms that are wholly dependent on forested ecosystems.

\subsection{Measurements needs for carbon and biodiversity}

We have referred to biomass and biomass change, as the information that is vital for reducing the uncertainty in surface-atmosphere carbon exchange estimates, hence future climate change uncertainty; and to vegetation 3D structure as the information needed to better understand changes in habitability and biodiversity, as well as biomass and biomass change. This section will concern itself with describing the general measurement types required to obtain this information. In Section 3 we will quantify these measurement requirements.

The measurements needed are (1) direct in situ measures of forest biomass and structure by weighing or measuring tree height etc., for calibration and validation of, (2) the remote sensing lidar and radar measures of 3D forest characteristics related to biomass. We will describe in this section the information required to address the science issues posed in Section 1.2: spatially contiguous maps of biomass and biomass change, with spatial resolutions on the order of a kilometer, at both regional to global scales. The biomass observations must be separated sufficiently in time for biomass change to be measureable by the remote sensing instruments employed. As we will see in Section 2 and in Section 3, this will require the spatial resolution 
of the remote sensing sensors and in situ measurements to be on the order of $25 \mathrm{~m}$.

Because the biomass and structure information products required are contiguous regional and global maps, direct measures of these by in situ measurements of structure and weighing sacrificed trees are obviously far too labor intensive to be practical. Rather, the biomass and structural information needs described in Section 1.2 require an analysis framework using remote sensing together with in situ inputs to extrapolate direct biomass and structural measures at the tree level to regional and global scales to produce spatially contiguous maps at fine spatial resolution. The remote sensing component of the analysis framework relies on lidar samplers and radar and passive optical imagers to sample and map landscape vegetation spectral and spatial "metrics" at high spatial resolution $(\sim 25 \mathrm{~m})$. To relate the lidar and radar measures or "metrics" to in situ measures, lidar and radar measures are then regressed against in situ timber height and volume measures in sample plots (Kohler \& Huth, 2010). The resulting regression equations are used to convert landscape level lidar and radar metrics into regional, contiguous biomass and 3D vegetation structure products. Finally, an independent set of ground plots must be held aside for validation and error characterization of the remote sensing measurements. In Sections 1.3.1 and 1.3.2 below, we will describe the specific spatial and temporal resolutions and coverage requirements needed for the remote sensing measurements.

\subsubsection{Vegetation structure, biomass and biomass change}

Within forests above ground biomass AGBM accounts for 70-90\% of the total, most of it in trees (Cairns et al., 1997). Throughout this paper, biomass and AGBM will be used interchangeably. The biomass of an individual tree is the product of its above ground volume $\left(\mathrm{m}^{-3}\right)$ and its average mass density $\left(\mathrm{kg} \mathrm{m}^{-3}\right)$. The biomass of all trees in a plot is the sum of the individual's biomass, which is approximately the product of their aggregated individual timber volume in the plot and their average volumetric density. Both can be measured destructively, however doing so is a very labor-intensive proposition. In lieu of destructive methods, biomass can be reliably estimated using allometry with much less, but yet considerable labor.

Allometry uses non-destructive measures (e.g., tree height and diameter) to estimate timber volume and published values for wood density $\left(\mathrm{kg} \mathrm{m}^{-3}\right)$. The product is biomass. Allometric relations are developed using regression from plots for which both arboreal structural variables (individual bole diameters, tree heights etc.) and sacrificed tree biomass data are available. Chave et al. (2004) found that 1 ha plots are reasonable and practical with accuracies of 18 to 33\% depending on the accuracy of wood density information.

Allometric equations have been established for boreal and temperate forests (Jenkins et al. 2003; Ter-Mikaelian \& Korzukhin, 1997) as well as tropical forests (Chave et al., 2004). Jenkins et al. combine an ensemble of allometric equations to develop generalized equations for large areas of North American forests. Chave et al. generalize over different tropical forests globally. Allometric equations have been validated extensively at the plot level yielding biomass accuracies of a few percent (Ter-Mikaelian \& Korzukhin, 1997).

To scale from plot-level allometry to regional scales requires a probability sampling strategy. In North America, the Forest Inventory Agency (FIA) Program employs such a strategy designed for regional and national reporting units. In foreign regions, plots may be allocated even more sparsely than in the US and worse, not necessarily allocated in an unbiased manner. The resulting biomass and structure maps from a probability sample framework are generally not fine enough spatially to allow a mechanistic understanding of the biomass variation with topographic, edaphic and climatic gradients, which can vary at scales of $\mathrm{km}$ and finer (Achard et al., 2002; Baccini et al., 2004; Brown et al., 1993; Brown \& Lugo, 1992; DeFries et al., 2002;
Fearnside, 1992; Houghton et al., 2007, 2009; Hurtt et al., 2010; Iverson et al., 1994; Myneni et al., 2001; Saatchi et al., 2007a, 2007b).

Biomass change is a balance between losses in biomass from disturbance and gains from subsequent regrowth. The forest is a carbon source when ecosystems are disturbed and a sink when recovering or growing. Forest carbon source strength is also related to its biomass, which controls the magnitude and rate of autotrophic respiration. Biomass change can be estimated by two means: by observing and differencing changes in 3D structure over time; or, by using structure values observed at one date as inputs to growth models that use climate and other physiognomic variables to model future growth and atmospheric carbon exchange. The observed temporal differences in forest carbon stocks can be used as inputs to inventory models to estimate carbon emissions to the atmosphere in the form of $\mathrm{CO}_{2}, \mathrm{CO}$, and $\mathrm{CH}_{4}$.

The use of ecosystem growth models to estimate biomass change requires a 3D structure map to initialize the models. Additional years of observations can be used to calibrate and validate the models. Based on the initial conditions, models simulate forest succession and estimate carbon stocks and associated, time-dependent fluxes of carbon between the atmosphere and the surface (Hurtt, et al., 1998; Hurtt et al., 2002; Hurtt et al., 2004; Hurtt et al., 2010; Moorcroft et al., 2001). For each patch in a landscape the rates of structural and biomass change following disturbance depend on the (1) vegetation state pre-disturbance (2) type of disturbance (3) lapsed time since disturbance, (4) composition of the regenerating vegetation (5) its physiognomy (primarily soils and topography) and (6) extant climate conditions.

Inputs to both inventory and growth models require remote sensing estimates of forest 3D structure at the scale of disturbance, and scales where regrowth rates are reasonably homogeneous. The scale varies depending on the various disturbance types. According to FAO (2006) fire disturbs about $~ 1 \%$ of the global forested area each year; wind throws another $\sim 1 \% \mathrm{yr}^{-1}$; insect/disease damage $\sim 3 \% \mathrm{yr}^{-1}$; deforestation and land conversion $0.2 \% \mathrm{yr}^{-1}$. Afforestation adds to forest area $\sim 0.1 \% \mathrm{yr}^{-1}$. FAO (2006) reports that the area of 'modified natural forest' is globally about $50 \%$ larger than the area of 'primary forest'. These various modalities of disturbance can occur at scales as fine as single trees (wind-throw, mortality and selective logging) to many kilometers in extent as a result of fire and clear-cutting. Regrowth occurs one tree at a time, but homogeneity in regrowth rates often occurs at scales on the order a kilometer as a result of management practices, the homogeneity of landscape characteristics, soils, topography and environmental factors; regrowth rates are also a function of disturbance type and preceding land use history, both important in determining the suitability of the soil substrate suitable for growth (water holding capacity, carbon content etc.). Ecosystem simulation models incorporating these factors together with $3 \mathrm{D}$ structure measurements to constrain them, will be central to prognosticating future trends in carbon exchange to the atmosphere, and future climate. Sensitivity studies based on these models show that biomass and flux estimation errors are minimized when the scale of mapping matches important scales of vegetation dynamics and underlying environmental gradients, operationally about 1 ha in complex environments (Thomas et al., 2009, 2010).

As will be discussed in section 3, to address the science issues posed in Section 1.2 the desired information are spatially contiguous maps of biomass and biomass change, at spatial resolutions of 25 to $100 \mathrm{~m}$; however, even spatial resolutions on the order of 250 to $1000 \mathrm{~m}$, at both regional to global scales would provide greatly improved information over that currently available. The biomass observations must be separated sufficiently in time for biomass change to be measureable by the remote sensing instruments employed. As we will see in Section 2 and in Section 3, this will require the actual spatial resolution of the more fundamental remote sensing and in situ measurements to be on the order of $25 \mathrm{~m}$. 


\subsubsection{Vegetation structure, biodiversity and habitat}

Many of the measurements of vegetation 3D structural variables needed for biomass and biomass change information are the same ones needed for habitat and biodiversity studies vertical distribution of foliage and wood, diameter at breast height (DBH) and basal area. The vertical dimension required for biodiversity studies is the bottomto-top configuration of forest vegetation (Brokaw \& Lent, 1999), which in turn may be characterized by observable variables such as canopy cover, tree and canopy height, vegetation layers, and biomass or volume. Structure in the horizontal dimension is the spatial heterogeneity of interacting patches of woody vegetation differing between patches in their structures and compositions, often described by patch metrics or spatial statistics (Gustafson, 1998).

The two primary components of vegetation 3D structure - vertical forest structure and horizontal forest heterogeneity - are known to underlie habitat selection by many animal species, as well as influence patterns of diversity of animals and other plants (Brokaw \& Lent, 1999; Macarthur et al., 1966; Tews et al., 2004; Verner et al., 1986). In terms of plants, vegetation community diversity is often expressed through the complexity of vegetation structure within forests, which is in turn linked to the functioning and health of Earth's terrestrial ecosystems (Franklin et al., 1989; Ishii et al., 2004). Animal biodiversity may act as "bioindicators" of the health of natural forests or the success of different vegetation structure-based techniques to manage forests ecologically and sustainably (e.g. thinning treatments or maintaining even vs. uneven-aged forest patches; Maleque et al., 2009).

Vertical canopy profiles may also shed light on serious cases of insect defoliation that alters vertical foliage complexity. Vertical complexity has been described through the use of the Foliage Height Diversity index (FHD; MacArthur \& MacArthur, 1961). The FHD statistic is intended to explain both the density and height distribution of foliage in a vegetation profile and is given as:

$\mathrm{FHD}=-\sum p_{i} \log _{e} p_{i}$

where $p_{i}=$ proportion of horizontal vegetation coverage in the ith vertical layer, summed over the number of homogeneous structural layers.

\section{Remote sensing of $\mathbf{3} \mathbf{d}$ vegetation structure}

The National Research Council recommended in its Decadal Survey Report that NASA develop a space-based lidar and radar capability to measure the 3D structure of the Earth's terrestrial ecosystems (Fig. 4). Instruments recommended were:

- A sampling, profiling lidar that can measure vegetation height profiles, as well as the height of non-vegetated solid earth and ice surfaces within plots along transects.

- An L-band pol-SAR sensor also potentially capable of measurements needed to infer vegetation biomass, and structure.

A lidar instrument emits nanosecond pulses of coherent light at the characteristic wavelength of its lasers. For DESDynI the lasers are planned to operate at $1064 \mathrm{~nm}$. Within the lidar, a number of lasers emit beams of photons in a near-nadir direction. Then photons are scattered by the land surface and vegetated structures back to the lidar telescope and detectors on board. The round trip time for the scattered photons is clocked, and multiplied by the speed of light to calculate the distance to their various scattering events. The relative intensities of returned photons at various times are recorded to obtain a relative intensity profile (shown in the middle panel of Fig. 4). Given sufficient laser energy in a pulse to penetrate the canopy, the difference in distance between the first scattering event (canopy tops) and the last scattering event (the underlying terrain surface) can be used to measure the average height of the trees within the pixel and the vertical distribution of scattering surfaces in the canopy. Each laser "measurement" is a profile of detected scattered relative light intensity versus relative range, i.e. distance from the last return (presumably the ground). Various metrics related to the profile can then be used to characterize vertical structure and related to biomass (Sections 1.3.1 and 2.1).

Lidar instruments have been demonstrated capable of estimating biomass in some of the denser dry tropical forests (Drake et al. 2002a, 2000b, 2003). The pixel or spot size is determined by the instrument optics that shapes the laser beams. The main limitations of currently available lidar technology are two-fold. First, while lidar imagers are being flown from aircraft, fully imaging lidar technology is not yet sufficiently mature to be flown in orbit; only multi-beam laser samplers are space-qualified. Second, successful lidar measurements require sufficiently transparent atmospheric conditions for the laser pulse to penetrate the atmosphere, the canopy and back to obtain a useable lidar profile.

A number of methods have been developed to relate various "metrics" or characteristics of the lidar profile to vertical vegetation structure and biomass. The methods, accuracies and limitations will be discussed in Section 2.1.

Radar emits coherent pulses of polarized electromagnetic radiation (at a much lower frequency and longer wavelength than lidar) (e.g. $1.25 \mathrm{GHz}$ or $\sim 21 \mathrm{~cm}$ ) and measures the energy fraction of each pulse returned in particular polarization orientations that is backscattered from limbs, trunks and ground beneath a forest canopy. The centimeter-long wavelength of a radar and its off-nadir orientation preclude a vertical profile as with lidar. Rather, the backscattering coefficient for a single pulse is determined by the entire canopy volume scattering the radar signal. However, a SAR creates an image by using a complex processing technique to emit and process the radar pulses. But the processing technique requires that the landscape be imaged along an off-nadir swath parallel to the satellite orbital track. The fraction of each SAR pulse that is backscattered, and the degree to which its polarization has been altered by the target, are rich in information about the $3 \mathrm{D}$ vegetation structure. Because the intervening atmosphere is relatively transparent at the L-band frequency, pol-SAR can provide wall-to-wall seasonal to annual observations of the global distribution of vegetation, particularly disturbance events, even under cloudy conditions.

Limitations of a SAR include the inability to penetrate very dense, tall forest canopies or obtain directly a vertical profile of vegetation distribution. A number of algorithms have been developed to relate the strength and polarization of the radar signal to vegetation structure and biomass. These will be described in Section 2.2.

Neither a lidar nor SAR measures biomass directly. Their signal structures are a function of vegetation structural variables, which in turn can be related to biomass either statistically, or using physicallybased models through allometric relations (Section 1.3.1). By combining data from both radar and lidar through data fusion, information on the overall fine-scale variability of the vertical and horizontal distribution of vegetation cover can be extended to denser canopies. Fusion algorithms can potentially utilize the strongest characteristics of each instrument; the denser canopy penetration ability of lidar to ensure accurate biomass estimates, even in highdensity biomass ecosystems, and the cloud penetrating, wall-to-wall imaging capability of the pol-SAR. Data fusion approaches will be described more fully in Section 2.3.

In just the last two decades, advances in the use of interferometric radar techniques utilizing multiple L or C-band pol-SAR (pol-InSAR) images acquired nearly simultaneously at two or more view geometries from aircraft have demonstrated a capability to map the 3D structure of forests (Cloude \& Papathanassiou, 1998; Neef et al., 2005; Papathanassiou \& Cloude, 2001; Treuhaft et al., 1996; Treuhaft \& Siqueira, 2000). L-band pol-inSAR has also shown promise to map structure in higher density regions of the tropics (Hajnsek et al., 


\section{Changes in landscape spatial heterogeneity - vegetation type, height profiles and biomass relate strongly to ecosystem state and condition.}

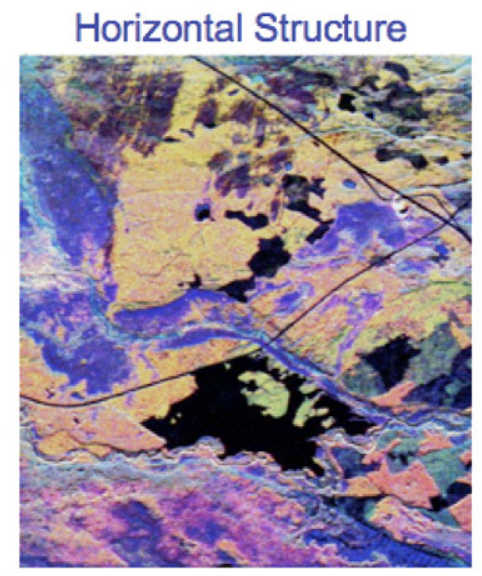

Forests tend to be patchy due to natural and human disturbance. In this radar image from Canada there is evidence of fires ( dark areas at top) and logging (e.g.,black features in center)

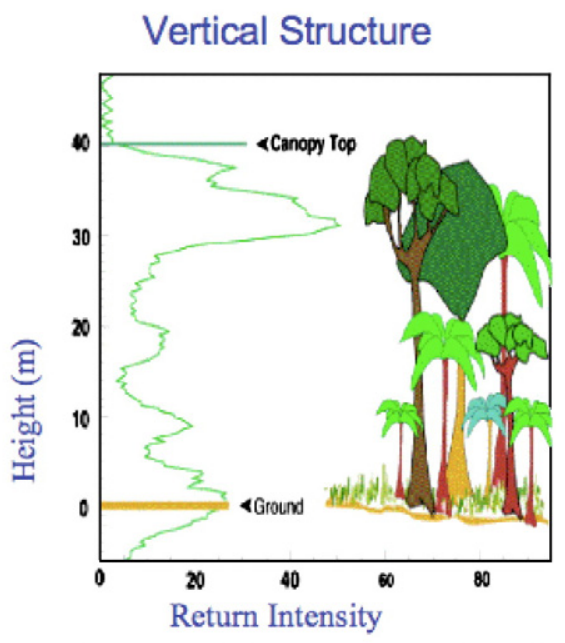

The vertical dimension provides key insight into ecosystem state and function based on the heights of canopy and understory
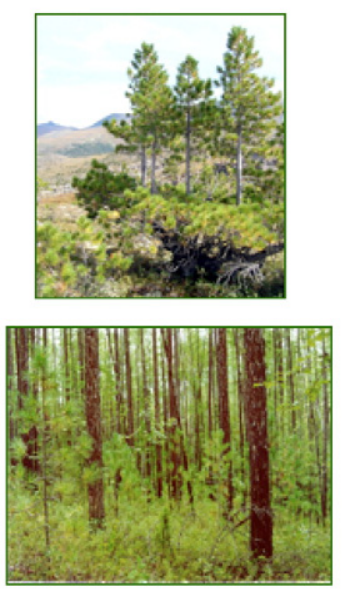

Ecosystem structure may change in response to climate. Top - change in tree form from bush to erect Bottom - new species appearing in the understory of this larch forest in Siberia

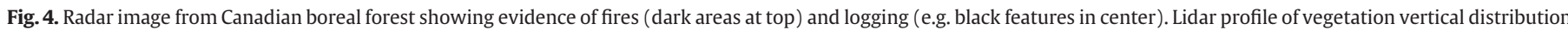
provides key insights into ecosystem state and function. Ecosystem structure changes in response to climate.

2009). Pol-Insar data will be available with the DESDynI mission. To the degree that decorrelation of the vegetation signal between overpasses is not problematic, pol-Insar can potentially provide 3D structure. As opportunities arise to coordinate the DESDynI mission with another pol-SAR mission a tandem-L-band option could be pursued to mitigate decorrelation, but as of this writing, an international collaboration would be required since a dual-platform mission is not in NASA's Decadal Survey plan.

\subsection{Lidar measures of structure and biomass}

Various lidar "metrics" related to canopy structure can be generated by characterizing the vertical structure of the lidar profile (Fig. 4). Two different relative height ( $\mathrm{RH}$ ) lidar metrics (relative to the ground return) are frequently employed in the estimation of biomass; (1) RH100 the height relative to the ground from which $100 \%$ of the lidar pulse energy is returned (2) RH50, the height relative to the ground for which $50 \%$ of the lidar energy is returned (Drake et al., 2003; Dubayah et al., 2000; Lefsky, 1999a, 1999b; Means et al., 1999; Nelson et al., 2005; Nilsson, 1996; Pang et al., this issue). The studies just cited used aircraft lidar data to show that RH100 is closely related to the tallest trees in a forest stand, and in turn is correlated with the above ground biomass in the stand. Repeated aircraft lidar observations of the same ground target in conifer stands in the Sierra Nevada on level ground show that RH metrics can be measured with a repeatability of about $1 \mathrm{~m}$. Ground elevation was located with a precision of $0.1 \mathrm{~m}$. Most of the variability between measurements resulted from variability in canopy tops. (Bryan Blair Private Communication).

Lidar studies have also demonstrated that canopy height metrics are correlated to bird species biodiversity. Relationships between avian biodiversity and lidar structure metrics (Fig. 5) from the Laser Vegetation Imaging Sensor (LVIS) were analyzed (Goetz et al., 2007). In the two major ecosystem types studied (forest and scrub/second growth), distinct relationships were found between vegetation height and species richness.

While imaging lidar instruments are available and have been flown successfully aboard aircraft, the only space-qualified lidar technologies are instruments with a few beams to sample the landscape. In the DESDynI time-frame, a 5 to 7 beam lidar would be feasible and could potentially sample the landscape to estimate average regional-scale height metrics by sampling regularly spaced grid cells covering the globe. The lidar height metrics are in turn related through allometry to biomass (see Section 1.3.1 for discussion). Biomass could also be estimated using ecosystem-based models to relate RH100 and other metrics to biomass. Studies have shown that accuracies of about $1-2 \mathrm{~m}$ are required to achieve a biomass estimation precision of $20 \mathrm{Mg} \mathrm{ha}^{-1}$ (Thomas et al., 2006, 2008). As shown in Fig. 6 the average standard deviation in the height metric RH100 measured from aircraft lidar over $1 \mathrm{~km}$ areas, for a range of biome types, is about $7 \mathrm{~m}$. Thus, the sample error within a grid cell will dominate the lidar RH100 measurement error of 1 to $2 \mathrm{~m}$ and orbital design must ensure adequate numbers of sufficiently cloudfree lidar samples to achieve aggregate height accuracies of 1-2 $\mathrm{m}$ in each grid cell. It will however be possible to trade grid cell resolution vs. biomass estimation accuracy. This will be discussed more fully in Section 3.1.2.

\subsection{Biomass measures using Pol-SAR}

The sensitivity of polarized L-band $(\sim 1.25 \mathrm{Ghz})$ Radar signals to forest structural attributes such as wood volume and basal area renders polarized synthetic aperture radar (Pol-SAR) suitable for inferring biomass, using nonlinear regression models, by relating measured cross-polarized backscattering coefficients to ground or lidar measures of biomass (Ranson \& Sun, 1997; Saatchi et al., 2007a, 2007b). Current state-of-the-art in radar technology permits L-band measurements from space with high spatial resolution $(25-100 \mathrm{~m})$ 

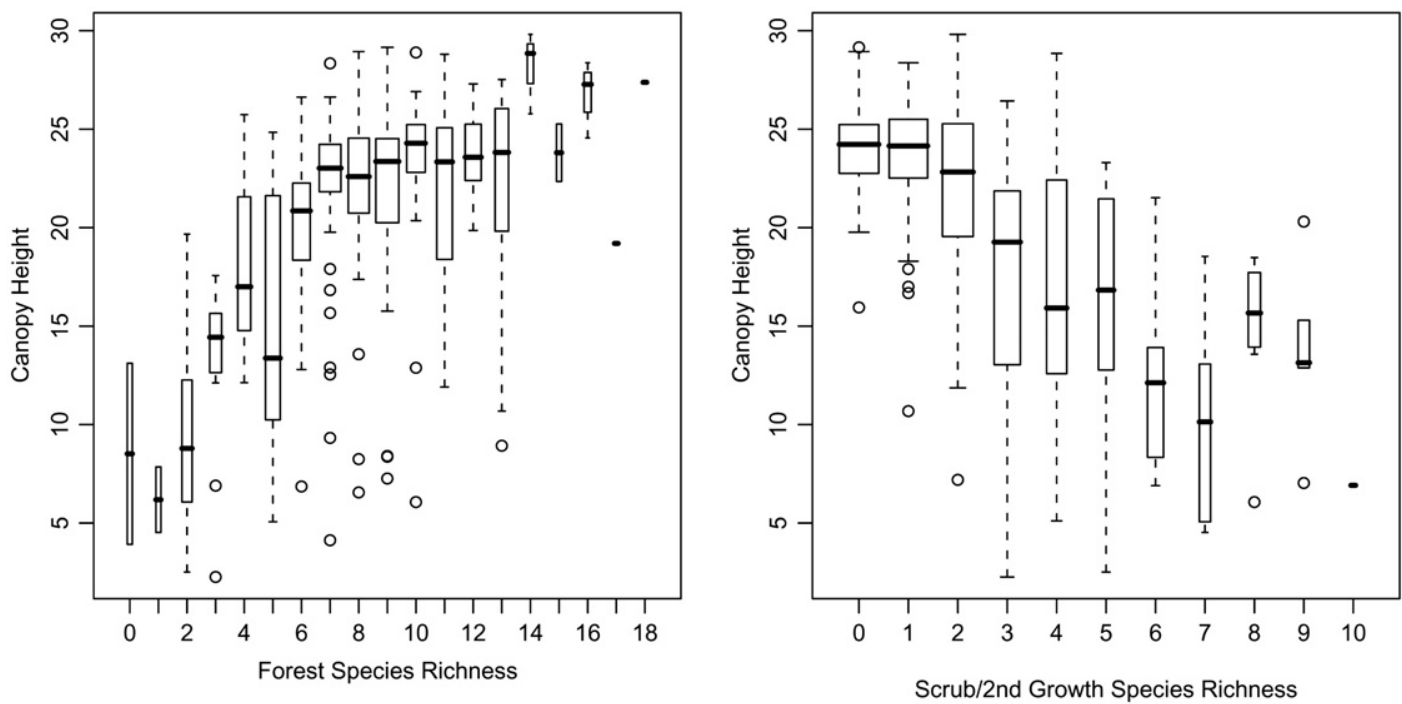

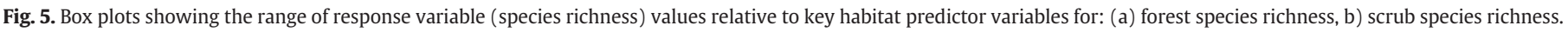

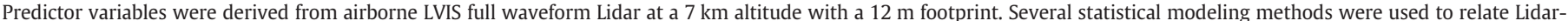

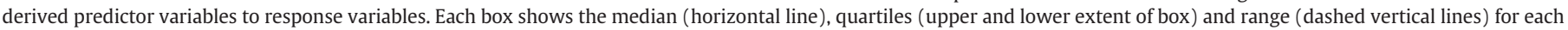

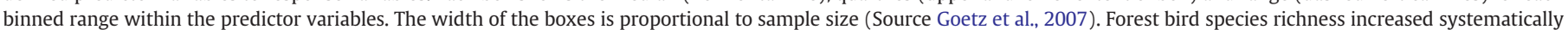

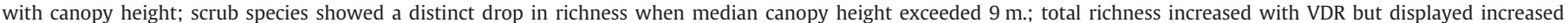
between-class variability at higher VDR values (Goetz et al., 2007).

both day and night regardless of atmospheric conditions and cloud cover, and with a repeating global coverage at monthly to seasonal intervals.

Radar sensitivity to canopy biomass ceases for moderate to dense canopies where the signal no longer penetrates through the entire canopy. This biomass level, the so-called saturation level, depends on the frequency, the polarization mode, incidence angle, the type of forest, foliage structure and moisture conditions. As a result, a wide range of sensitivities has been reported. L-band polarimetric algorithms have been reported to estimate biomass with 20\% accuracy up to $100-150 \mathrm{Mg} \mathrm{ha}^{-1}$ in boreal, temperate and woodlands and up to $100 \mathrm{Mg} \mathrm{ha}^{-1}$ in tropical forests (Kasischke et al., 1997; Mitchard et al., this issue, 2009; Saatchi et al., in press). L-band pol-InSAR has demonstrated sensitivities up to $250-300 \mathrm{Mg} \mathrm{ha}^{-1}$ (Neef et al., 2005; Treuhaft et al., 1996).

In addition to measuring one-time biomass densities, pol-SAR also provides the capability of monitoring biomass changes resulting from

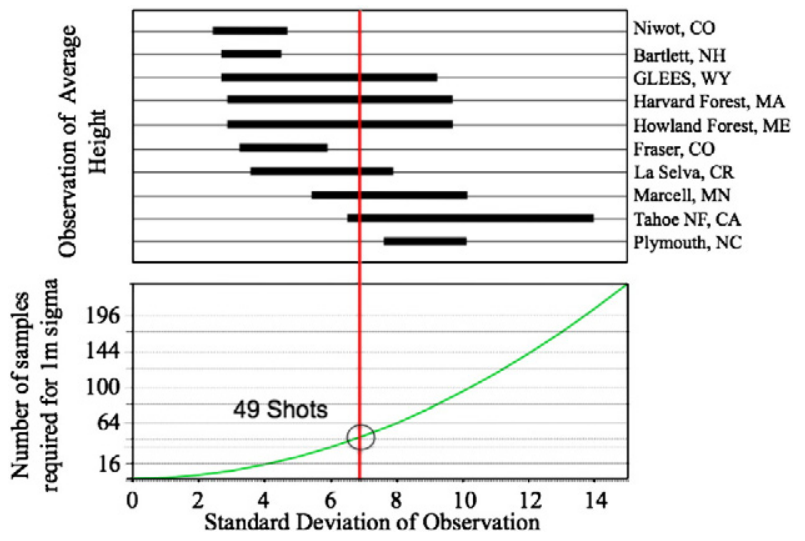

Fig. 6. Height variability in $1 \mathrm{~km}$ cells for various study regions as calculated from LVIS data (Lefsky unpublished). Standard deviation in height average is about $7 \mathrm{~m}$. Thus to achieve a $1 \mathrm{~m}$ accuracy in similar cells would require 49 samples for a 1 sigma error $\left(7 /(49)^{-1 / 2}\right)$. Vegetation ranges in composition from ecosystems dominated by needleleaf evergreen ( Niwot CO, Howland ME, Fraser CO, GLEES WY, Tahoe NF CA), mixed broadleaf deciduous (Bartlett NH, Marcell MN, Plymouth NC) to tropical forest (La Selva CR). clear-cutting, forest fires, insect disturbance, wind damage, and to some extent more subtle changes in forest structure (Couturier et al., 2001; Ranson et al., 2003; Rignot et al., 1994; Saatchi et al., 1997; Salas et al., 2002; Siegert et al., 2001). Biomass losses can be quantified by either using a direct method differencing two sequential biomass maps to calculate change or by employing established Pol-SAR change detection algorithms (Lombardo \& Oliver, 2001; Rignot and vanZyl, 1993). Areas of rapid regrowth following disturbance (after $1 \mathrm{yr}$ for many areas, and after several years for more slowly growing areas) can be mapped and quantified using pol-SAR. Fusion with structural information from lidar along transects can be used to map and quantify biomass changes in areas of degradation, in areas undergoing slower regrowth and those undergoing little change. Precision of biomass change can be increased at coarser resolutions by accumulating lidar samples and by multi-looking (500-1000 looks) pol-SAR backscatter measurements to reduce speckle (Conradsen et al., 2003; Mitchard et al., in press; Rignot and vanZyl, 1993; Rowland et al., 2002).

The results from these studies summarize the accuracy of radar monitoring of forest disturbance and recovery and highlight various sources of errors and ambiguities. However the results support that backscatter polarimetric measurements can detect and map disturbance modes in most global forested ecosystems.

\subsection{Fusion of Pol-SAR measurements with lidar sampling}

Radar and lidar sensors provide complementary information about the forest structure. The volume of vegetation sensed by these two instruments at a pixel level differs. Nadir-pointing lidar measures a vertical vegetation profile along its orbital track. SAR requires that a scene be imaged at off-nadir view angles through a slanted volume accessing different canopy information. SAR provides wall-to-wall coverage, although saturating at lower biomass levels (100 to $150 \mathrm{Mg} \mathrm{ha}{ }^{-1}$ ) than lidar. A properly designed lidar signal can detect the ground to measure canopy height metrics and infer biomass in the densest of canopies found in the tropics.

While radar/lidar fusion algorithms are in the early stages of development, fusion between the lidar/radar measurements can potentially be exploited using algorithms that are primarily statistical 
in nature, or physically based approaches that exploit backscattering models relating vegetation properties to the strength and polarization of the scattered signal.

1. Radar backscatter or Pol-InSAR measurements can be combined with lidar height metrics in statistical regression models to estimate forest three-dimensional structure (height, biomass, volume, basal area) (Sun \& Ranson, 1995). This approach is dependent on ground inventory data to develop the statistical models and validate the results and hence requires careful assessment of the compatibility of inventory plot size and spatial resolution of remote sensing data.

2. Lidar measurements of vertical structure can be used as input to radar backscatter and pol-InSAR electromagnetic backscattering models that relate biomass to vegetation to constrain vegetation structural properties. The major driving parameters of these radar models are tree number per unit area and average tree heights in a stand (Liu et al., 2010; Richards et al., 1987; Sun et al., 1991; Sun \& Ranson, 1995). The use of a physically-based approach can potentially reduce the dependence on in situ measures. However, radar backscatter is also a function of canopy electromagnetic properties that can vary with soil moisture, dielectric properties etc., thus will certainly require some calibration using ground inventory data, although less so than purely statistical approaches. Physically-based approaches are well suited for multi-sensor applications, can directly process data from multiple dates, can account for variations in sensor position/geometries, and provide a comprehensive treatment of full scene components (e.g. trees, background) that influence spectral response. In areas of sloped terrain including steeper mountain areas, the physically based approaches can account for terrain slope and aspect.

The fusion of Pol-SAR wall-to-wall measurements with lidar samples can potentially provide enhanced biomass accuracies extending accurate biomass estimates to even denser forests.

In sparser forests (e.g., boreal ecosystems or savannahs) passive optical satellite remote sensing technology such as the MODerate resolution Imaging System (MODIS) and Landsat and other similar imagers can be added to the data fusion mix to augment the information from lidar and radar. MODIS and Landsat have been able to effectively map the 3D structure and characteristics of sparser forests: Landscape characteristics such as areal extent, disturbance rates, landscape pattern metrics such as shape, size, contiguity, edge density, and the vertical dimension, canopy crown dimensions and stem density (Peddle et al., 1999; Soenen et al., 2009; Widlowski et al., 2007) and biomass (Hall et al., 1997).

The fusion of active sensors with one another as well as the conjoining of active sensor-information with information obtained from the existing constellation of passive remote sensing devices is currently limited by the lack of contemporaneous data acquisitions by both sensor types at locations with well developed ground data. This will likely be an ongoing area research for several years to come.

\section{Measurement requirements}

For which forest ecosystems does structure, biomass and biomass change need to be measured or modeled and with what accuracy to produce improved biomass and biomass change information? How accurate do the measurements need to be? The information needs and measurement types specified in Sections 1.2 and 1.3 are generic, not mission dependent. But the quantitative needs specified here are influenced by the state of the art in lidar and radar capability to measure structure and biomass. The requirements will also guide instrument design considerations (power, instrument lifetimes, number of lidar beams, radar polarization and signal to noise etc.) and the capabilities of launch vehicles, spacecraft etc..

Which elements of the global forested landscape must be measured to reduce the uncertainty, locate and understand the underlying causes of the terrestrial sink and the land use contributions of Fig. 1? Although the magnitude of the residual terrestrial "sink" is inferred as a residual of other terms in the budget, the fact that it is a "sink" implies that it must result from carbon gain in either secondary ("recently" disturbed) or primary older forests. While carbon storage in croplands soils is important, the contributions to global carbon flux, even in the US are small in comparison to forested ecosystems or regions of woody encroachment (Pacala et al., 2001).

For forested ecosystems over a specified reporting period $R$, the net terrestrial uptake $\Delta C_{R}$ globally is the sum over all landscape elements (or patches) of the above ground carbon loss $\Delta \mathrm{C}_{\mathrm{i}}\left(\mathrm{Mg} \mathrm{ha}^{-1} \mathrm{yr}^{-1}\right)$ in each of the elements of area $\mathrm{A}_{\mathrm{i}}$ and the above ground carbon gain from regrowth. Carbon loss must be adjusted for $\Delta S_{R}$, the subsequent changes in carbon pools following loss - plants, soil, wood products, and detritus. Patches are landscape elements or strata relatively "homogeneous" in structure, biomass and growth rate. Above ground carbon gain is the product of the area of the ith patch $\mathrm{A}_{\mathrm{i}}$ and its net ecosystem production $\mathrm{NEP}_{\mathrm{i}}$ in $\mathrm{Mg} \mathrm{ha}^{-1} \mathrm{yr}^{-1}$. Only the above ground component of NEP $\mathrm{P}_{\mathrm{i}}$ can be measured using remote sensing, thus below-ground carbon change must be estimated using carbon models. The storage and decomposition term $\Delta S_{R}$ is somewhat complex but represents the loss of carbon to the atmosphere from wood products and litter decomposition, which must also be modeled. Expressed mathematically,

$$
\Delta \mathrm{C}_{\mathrm{R}}=\sum \mathrm{A}_{\mathrm{i}}\left(\mathrm{NEP}_{\mathrm{i}}-\Delta \mathrm{C}_{\mathrm{i}}\right)-\Delta \mathrm{S}_{\mathrm{R}}
$$

which can be further decomposed into components measureable by remote sensing and/or quantifiable by modeling as follows.

$\Delta \mathrm{C}_{\mathrm{i}}$ can be decomposed into biomass loss from rotation logging $\Delta \mathrm{C}_{\mathrm{il}}$, biomass loss from "permanent" land use conversion $\Delta \mathrm{C}_{\mathrm{ip}}$ and loss from natural disturbance $\Delta \mathrm{C}_{\mathrm{id}}$. A similar decomposition can be effected for $\mathrm{NEP}_{\mathrm{i}}$. Eq. (2) then can be written as

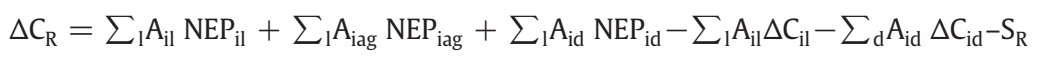

where $A_{\text {iag }}$ is the area converted from abandoned agriculture to forest, and $\mathrm{NEP}_{\text {iag }}$ is the net ecosystem production of that patch.

With terms on the right hand side of Eq. (3) collected to match the components of the global carbon balance of Fig. 1, $\Delta \mathrm{C}$ may be expressed as,

$$
\sum_{\mathrm{l}} \mathrm{A}_{\mathrm{il}}\left(\mathrm{NEP}_{\mathrm{il}}-\Delta \mathrm{C}_{\mathrm{il}}\right)+\sum_{\mathrm{p}} \mathrm{A}_{\mathrm{iag}} \mathrm{NEP}_{\mathrm{iag}}-\sum_{\mathrm{p}} \mathrm{A}_{\mathrm{ip}} \Delta \mathrm{C}_{\mathrm{ip}}-\Delta \mathrm{S}_{\mathrm{R}} \sum_{\mathrm{d}} \mathrm{A}_{\mathrm{id}}\left(\mathrm{NEP}_{\mathrm{id}}-\Delta \mathrm{C}_{\mathrm{id}}\right)
$$

Rotation logging + Recovering abandoned cropland-Permament change-storage \& decay + Natural disturbance and recovery 
For which forested ecosystems are the measurements needed to locate the terrestrial sink, the land use sources and understand the underlying causes? Tropical secondary forests and post-disturbance recovery from logging and fire in boreal and temperate regions are the major carbon sinks. Estimating regional and global carbon flux requires observations to provide a wall-to-wall initial biomass inventory, then updated at least annually to identify the various causes of biomass change using direct observations and/or combined with models. The global biomass inventory needs to be at a relatively fine spatial scale ( 1 ha desired to $1000 \mathrm{~m}$ required). To capture the entire range of disturbance events from selective logging, insect and disease observations are needed at even finer spatial resolution (Houghton et al., 2009). Annual global coverage is necessary to develop an inventory of type, size, frequency, and interannual variability of these processes.

How can the terms in Eq. (4) be measured or modeled? The first sum in Eq. (4) is the net above ground carbon change from rotation logging; the second sum carbon uptake on lands where conversion from agriculture to forests has occurred; the third term is carbon loss where "permanent" loss of forest has occurred, the fourth term subsequent changes in carbon pools (plants, soil, wood products, and detritus) and the fifth term, carbon change from natural disturbances in forests and subsequent recovery. $\mathrm{NEP}_{\text {id }}$ is a function of not only climate change, but also changes in environmental conditions affecting growth or physiological functioning (e.g. nitrogen and $\mathrm{CO}_{2}$ fertilization). $\mathrm{NEP}_{\text {id }}$ can be measured as biomass change over time, or can be estimated using ecosystem growth models. The land-use term in Fig. 1 is an estimate of the magnitude of the first four terms, and includes the uptake of carbon in secondary forests recovering from rotation logging and agricultural abandonment, but not the sources or sinks from natural disturbances.

The carbon sources and sinks resulting from land use change are calculated with carbon tracking models based on two types of information: rates of land use change and subsequent changes in carbon pools (plants, soil, wood products, and detritus). The major source of uncertainty is $\Delta \mathrm{C}_{\mathrm{ip}}$ the aboveground biomass loss from forests converted to other land uses, and it results from a lack of spatially specific estimates of biomass (Houghton, 2003; Houghton et al., 2007). Accurate estimates of aboveground biomass at the spatial resolution of land use change would greatly reduce the uncertainty in estimates of carbon flux from land use change. Thus, direct estimates of biomass and biomass change from satellite must focus on measuring the biomass lost from disturbance, and that gained from forest growth.

With a proper satellite design, all $A_{i}$ terms can be measured by radar and all $\Delta C$ terms using lidar from a probability sample to measure biomass prior to disturbance in "homogeneous" strata on the size of a few kilometers, and from radar to obtain biomass following disturbance. Radar can also obtain seasonal temporally-spaced measures of biomass change in each patch within a specified period of time, with the saturation limitations described in Section 2.2.

How accurately must the structure and biomass of forested landscape elements be measured? A reasonable global goal given present capability is to reduce the uncertainty in the terrestrial net flux of carbon to that of the uncertainty in the global net uptake by the oceans, which from Fig. 1 is $0.5 \mathrm{PgC} \mathrm{yr}^{-1}$. The net terrestrial uptake is the difference between (1) carbon input to the atmosphere from land use change and (2) the terrestrial "sink" (the residual imbalance among all other terms in Fig. 1). Given the individual uncertainties in these two terms, the rms uncertainty of the difference is $\sim 1.3 \mathrm{PgC} \mathrm{yr}^{-1}$. Reducing the uncertainty of the net terrestrial uptake that of the ocean would be a significant reduction.

Eq. (2) provides a framework within which to define the measurement requirements to measure $\Delta C_{R}$ to the specified accuracy of \pm 0.5 PgC yr ${ }^{-1}$. How accurately do we need to measure the terms inside Eq. (2), i.e. the area A, the NEP and the biomass loss from each patch sampled in the region? The error of an estimate of $\Delta B_{R}$ SE given $n$ observations within $R$ is to first order

$$
\mathrm{SE}=\left(\mathrm{MSE}_{\text {meas }}+\mathrm{MSE}_{\mathrm{samp}}\right)^{1 / 2} / \sqrt{ } \mathrm{n}
$$

where $\mathrm{MSE}_{\text {meas }}$ is the biomass measurement error for a sample, $\mathrm{MSE}_{\mathrm{samp}}$ is the sample error, the mean square difference in biomass from the total and the sampled population, and $\mathrm{n}$ is the number of pixels sampled by the lidar or radar.

A remote sensing system employing radar and lidar will have the capability to measure a very large number $\mathrm{n}$ of sample plots in a region, even a complete enumeration with radar. Thus, as seen in Eq. (5), even modest regional scales, the large number n of measurements will permit a reduction in the sample error, given an unbiased sample design, effectively to nil. Thus, the driver of SE at a regional scale is the measurement error, not sample error. However, if the measurement error itself is on average, unbiased, even the measurement errors become negligible over a sufficiently large region sufficiently sampled. But, there is no guarantee that either the lidar or radar measurements are unbiased, so the bias must somehow be measured or estimated in order to assess whether the regional level estimate is within a specified accuracy. Bias can result for example, from a consistent under or overestimate of the true biomass in the allometric equations, or bias in the ecosystem carbon models or their inputs, or measurement bias in either the radar or lidar. Bias cannot be estimated without comparing DESDynI estimates to a "gold standard" that is chosen to represent the "best estimate" of the "true" biomass. In DESDynI the gold standard will be biomass estimates from allometry and in situ measurements. Therefore, a validation program is essential, consisting of ground-measured structural and biomass values to be compared with those from lidar and radar. But ground truth is expensive. How many such sites will be required in order to assure that our remote sensing estimates are meeting the required accuracies over a region?

That is, as far as bias is concerned, if we want to ensure absolutely that the global carbon flux is within $0.5 \mathrm{PgC} \mathrm{yr}^{-1}$ of the "true" or gold standard value, or about $38 \%$ of the estimated net global terrestrial flux of $1.3{\mathrm{PgC} \mathrm{yr}^{-1}}^{-1}$, then the plot or patch level average overall bias must be $38 \%$ or less, simply because measurement bias does not decrease with the number of samples. Of course, bias will not be the same for every patch, and could in fact average out over many regions from overestimation in some, and underestimation in others. But there is no guarantee of this. As seen from Section 2.2, errors in denser old-growth tropical forest patches where radar saturation is an issue will likely be larger than in recently disturbed patches.

To allocate independent validation sites they should ideally be placed in the major global biomes of interest, and allocated in a manner to be representative of the biomes. Validation results will be specific to each biome, since each presents different problems in lidar, radar estimation. But how many such sites will be required to determine that the average estimation bias over the validation sites is $\pm 38 \%$ or less? Sufficient numbers of validation sites for estimating the bias are required to ensure that the standard error of the regression between the estimated $\Delta C_{R e}$ and the "true" $\Delta C_{R t}$ is $\leq \pm 38 \%$. The number of validation sites required will depend upon the precision of the estimate $\Delta C_{R}$.

In the remainder of this paper, we will address in detail the vegetation structural characteristics we need to measure to provide the needed information, and in this section, quantify the measurement accuracies, frequencies and spatial resolutions required, and finally, the data products 
Table 1

Biomass measurement goals and requirements.

\begin{tabular}{lll}
\hline Measurement goals/requirements & Justification/rationale & Verification method \\
\hline Global biomass: global 1 ha (but finer than $1 \mathrm{~km})$ & Critical to improving information on terrestrial carbon flux & Field campaigns in representative forests distributed \\
resolution biomass map with accuracies better & from respiration and loss from disturbance critical to reduce & around the world comparing in situ measurements to \\
than the greater of $10 \mathrm{MgC} \mathrm{ha}^{-1}$ or $20 \%$, not to & $\begin{array}{l}\text { the uncertainty of the land use and terrestrial sink terms of the } \\
\text { exceed } 25 \mathrm{MgC} \mathrm{ha}^{-1}\end{array}$ & mission-derived biomass and biomass change estimates \\
\hline
\end{tabular}

envisioned from such missions. The measurement accuracies realized in an actual mission will depend on instrument performance, mission duration, orbital constraints and other elements of the final mission design, all constrained by cost. Therefore, in the following sections we will quantify the measurement accuracies in terms of desired and required accuracies denoting the upper and lower bounds of the information quality thought to be feasible from the spacecraft mission design. "Desired" cites are the desired quality of the information (upper bound), while "required" cites are the least acceptable quality (lower bound) of the information. Tables 1 through 3 summarizes all the measurement needs (desired and required), and the principal target products. The needs are interrelated, thus to some extent are redundant.

In Section 3.1 we will describe the measurements required to develop globally consistent and spatially resolved estimates of aboveground biomass and carbon stocks; in Section 3.2 those required to quantify changes in terrestrial sources and sinks of carbon resulting from disturbance and recovery (net terrestrial carbon flux) and in Section 3.3 the measurements required to characterize habitat structure for biodiversity assessments.

\subsection{Biomass and carbon stocks}

\subsubsection{Summary of core observables}

The desired biomass product required is a global map with a spatial resolution of $1 \mathrm{ha}$, but no worse than $1 \mathrm{~km}$, with an accuracy of $\pm 20 \mathrm{Mg}$ ha 1 ( $\pm 10 \mathrm{MgC} \mathrm{ha}^{-1}$ ) or $20 \%$, whichever is greater, with errors not in excess of $50 \mathrm{Mgha}^{-1}\left(25 \mathrm{MgC}^{-h \mathrm{~h}^{-1}}\right)$. For areas with biomass less than $100 \mathrm{Mg}$ ha ${ }^{-1}$, the required spatial resolution is 1 ha. Annual updates to the global biomass maps are required but the updates need not achieve the desired accuracies until a sufficient density of lidar samples has been acquired. The time frame will depend on the number of lidar beams and mission design.

Annual, spatially resolved biomass permits a direct measure of the rate of change in biomass, hence the carbon flux resulting from biomass loss from disturbance and the subsequent biomass gain from recovery. Fig. 7 (Saatchi et al. 2007) is typical of a landscape mosaic of disturbance and recovery following disturbance. Table 1 summarizes the biomass requirements.

Develop globally consistent and spatially resolved estimates of aboveground biomass and carbon stocks.

Because the lidar RH metrics and radar $\sigma$ metrics are non-linear in biomass (see Sections 2.1 and 2.2), it is straight forward to show from Eq. (6) that

$$
\Delta \mathrm{C}_{\mathrm{R}}=\sum \mathrm{A}_{\mathrm{i}}\left(\mathrm{NEP}_{\mathrm{i}}-\Delta \mathrm{C}_{\mathrm{i}}\right) \neq \mathrm{A}_{\mathrm{R}}<\mathrm{NEP}_{\mathrm{i}}>_{\mathrm{R}}-<\Delta \mathrm{C}_{\mathrm{i}}>_{\mathrm{R}}
$$

where $A_{R}$ is the estimated (from remote sensing) total regional forested area for $R,<N E P_{i}>R$ the average net primary production for $R$ and $<\Delta C_{i}>R$ the average regional biomass per unit area (again, the latter two from remote sensing). $\Delta C_{R}$ computed as products of regional averages can differ significantly from those same calculations made at the spatial resolution of disturbance and regrowth. Much of the annual deforestation over the Amazon basin, Fig. 7 (top), occurs at scales of 1 ha and below. Mapping the spatial distribution of disturbance and recovery at these scales to estimate biomass change can differ from a gross regional averaging approach by a factor of 2 (bottom right). A biomass distribution (bottom left) at the scale of $1 \mathrm{~km}$ resolution (Saatchi et al., 2007a, 2007b) over the Amazon basin corrected the average annual estimate from $0.38 \mathrm{PgC} \mathrm{yr}^{-1}$ to $0.23 \mathrm{PgC} \mathrm{yr}^{-1}$. The heterogeneity of ecosystems occurs at different scales and has been studied extensively to capture its magnitude and causes (Pastor, 2005). If these patterns cannot be mapped at sufficiently high spatial resolution, the relationship between current carbon stocks and future trends cannot be adequately resolved.

Spatially resolved biomass data will also be essential to initialize ecosystem models that estimate carbon stocks and associated, timedependent fluxes of carbon between the atmosphere and the surface. (Hurtt et al., 1998, 2002, 2004, 2010; Moorcroft et al., 2001; Houghton et al, 2001). Sensitivity studies based on these models show that biomass and flux estimation errors are minimized when the scale of mapping matches important scales of vegetation dynamics and underlying environmental gradients, operationally about 1 ha in complex environments. However, even coarser resolutions up to $1 \mathrm{~km}$ can provide superior information in comparison to current global estimates.

\subsubsection{Required measurement capabilities for biomass}

3.1.2.1. Global coverage of all forested ecosystems. The location of the land carbon sinks and sources based on inverse analyses agrees only zonally (e.g. northern vs. southern hemisphere, boreal vs. temperate vs. tropical, e.g. see Rodenbeck et al., 2003); thus, the precise causes of their annual swings in strength, on occasion as much as 100\% (Canadell et al., 2007) are unknown. To what degree are these large shifts a result of climate

Table 2

Biomass change measurement goals and requirements.

\begin{tabular}{|c|c|c|}
\hline Measurement goals/requirements & Justification/rationale & Verification method \\
\hline $\begin{array}{l}\text { Biomass change: map global areas of disturbance ( } 50 \% \text { loss of } \\
\text { biomass no worse than } 90 \% \text { ) at } 1 \text { ha resolution annually. A goal } \\
\text { with sufficient mission lifetime is to quantify a biomass gain of } \\
2 \text { to } 10 \mathrm{Mg} \mathrm{ha}^{-1} \mathrm{yr}^{-1} \text { at } 1 \text { ha resolution (no coarser than } 1 \mathrm{~km} \text { ) } \\
5 \text { yrs following last disturbance }\end{array}$ & $\begin{array}{l}\text { Global biomass change with these characteristics } \\
\text { is critical to improving information on terrestrial } \\
\text { exchange of carbon with the atmosphere }\end{array}$ & $\begin{array}{l}\text { Field campaigns in representative forests distributed } \\
\text { around the world comparing in situ measurements to } \\
\text { mission-derived biomass and biomass change estimates }\end{array}$ \\
\hline
\end{tabular}


variability, or disturbance? To address this question adequately, satellite assets are needed that can observe all global regions and provide an initial biomass inventory, then map disturbance and regrowth at least annually to identify the various causes of biomass change using direct observations or models.

3.1.2.2. Forest height with $1 \mathrm{~m}$ height accuracy (1 sigma) at zero slope. The original Vegetation Canopy Lidar mission (VCL; Dubayah et al., 1997) exploited the relationship between AGBM and canopy height. Numerous studies (Drake et al., 2003; Dubayah et al., 2000; Hyde et al., 2005; Lefsky et al., 2002) have validated this approach. Additionally it is the foundation of the Tandem-L concept. The accuracy requirement for height from VCL was documented and reviewed at various stages of the mission. In addition, modeling studies have confirmed the approach.

As described in Section 1.3, biomass may be estimated through statistical and ecosystem-based modeling. At scales of 1 ha, studies have shown that accuracies of about 1-2 m are required to achieve desired AGBM accuracies (Hurtt et al., 2010, Hurtt et al., 2004; Thomas et al., 2006, 2008). In addition, there will be a fusion requirement on height accuracy on a per shot basis, where lidar estimates of height are used to constrain radar based estimations.

3.1.2.3. Forest vertical structure: forest vertical structure (e.g. height of median energy return - HOME) in $25 \mathrm{~m}$ ground element accurate to $1-2 \mathrm{~m}$ of canopy height. This footprint size minimizes errors from blending too many trees, as well as errors that occur from slope effects. Realization of canopy gap structure is optimized when the observations match the spatial length scales of gaps in the forest and breadth of canopies of individual trees. Simulations have shown (Fig. 7 of Yang et al., Pang et al., this issue) that with nadir-pointing for lidar, $1 \mathrm{~m}$ height accuracy can be achieved with $25 \mathrm{~m}$ footprint on slopes up to $15^{\circ}$ and a $2 \mathrm{~m}$ height accuracy on slopes up to about $30^{\circ}$. As can be seen in the error simulation in the upper left of Fig. 8, off-nadir pointing beyond $4^{\circ}$ exceeds the one-meter rms height accuracy requirement for a large percentage of the world's forests (other graphics in Fig. 8). In addition to canopy height, it has been shown that for lidar, other metrics are required for optimal biomass estimation, such as HOME; these internal height quantiles should also be known to about $10 \%$ relative to canopy height (Drake et al., 2003 ; Dubayah et al., 2000; Hyde et al., 2005; Lefsky et al., 2002).

3.1.2.4. 1 ha resolution desired with $1 \mathrm{~km}$ required. Sufficient global coverage to obtain $1-2 \mathrm{~m}$ (1 sigma) height error for $1 \mathrm{ha}$ and $1 \mathrm{~km}$ grid cells. In certain regions of the world, especially in the tropics, forest biomass is known to exceed $100-200 \mathrm{Mg} \mathrm{ha}^{-1}$. In such cases, lidar has been shown to penetrate through the canopy to the ground beneath, providing a means to sample both canopy structure and height (Drake et al. 2002a, 2000b, 2003). Modeling studies (Hurtt et al., 2004; Thomas et al., 2008) suggest that a height accuracy of 1 to $2 \mathrm{~m}$, depending on biome, leads to biomass estimation accuracy on the order of $10 \mathrm{MgC} \mathrm{ha}^{-1}$. For very high-biomass areas, estimation algorithms may need to rely on lidar observations

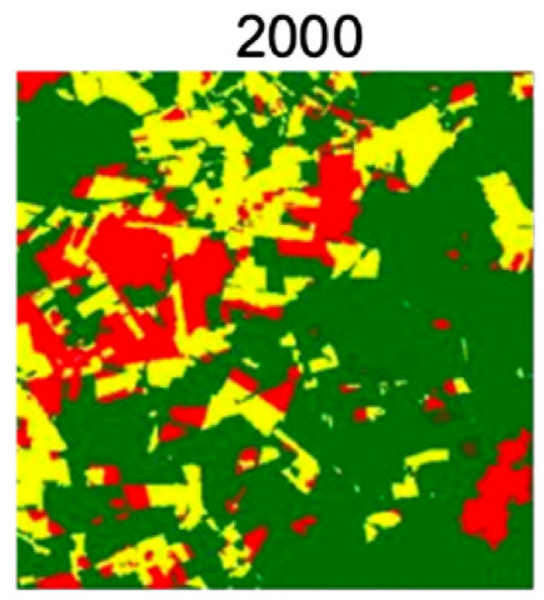

$25 \mathrm{~km}^{2}$

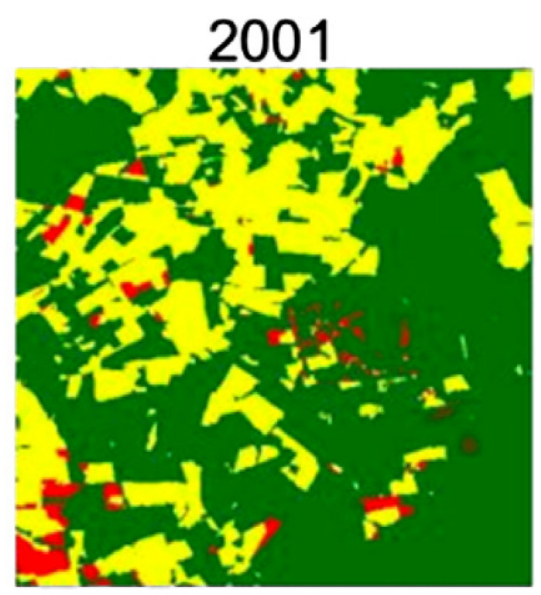

$25 \mathrm{~km}^{2}$

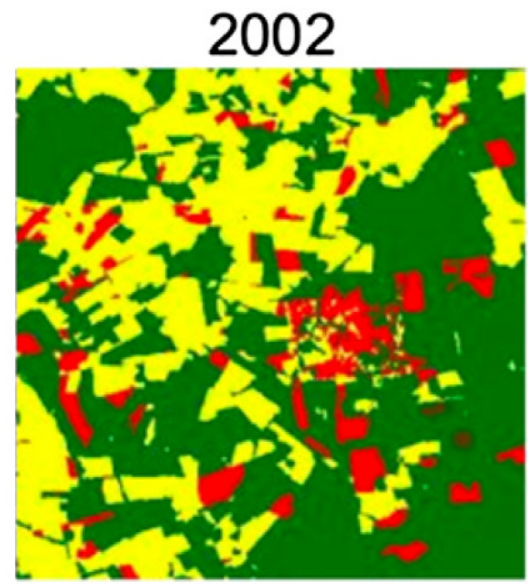

$25 \mathrm{~km}^{2}$
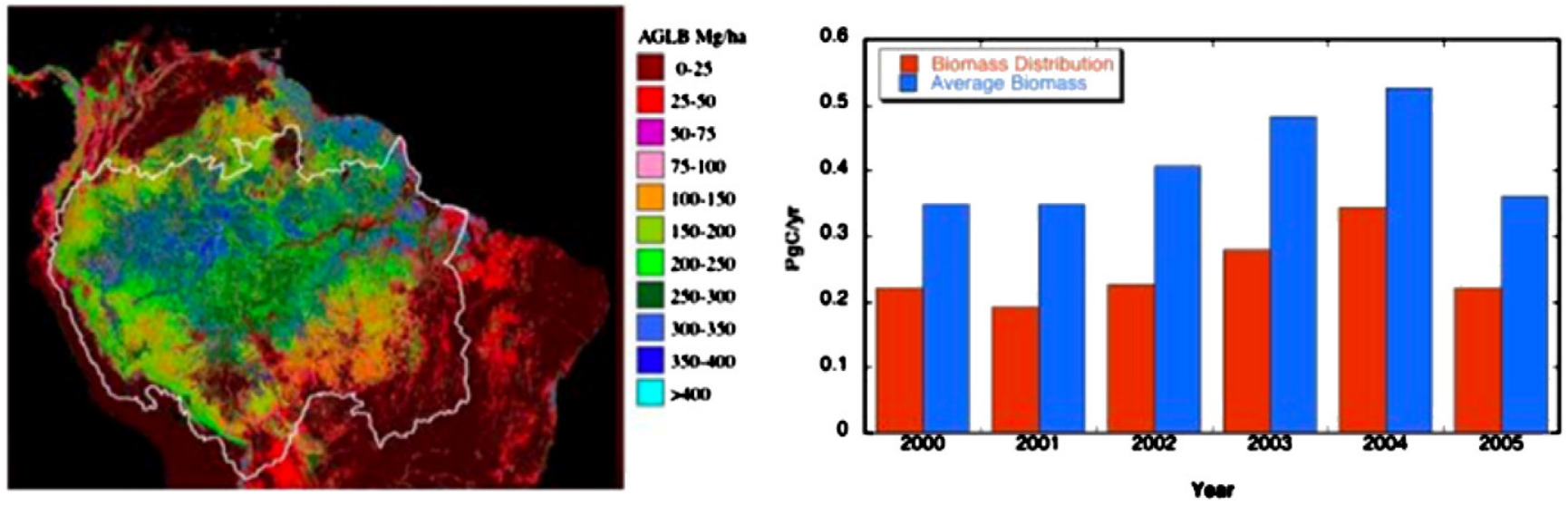

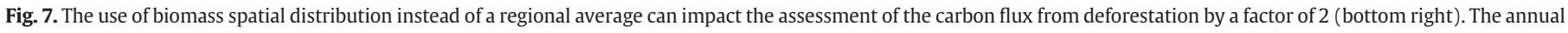

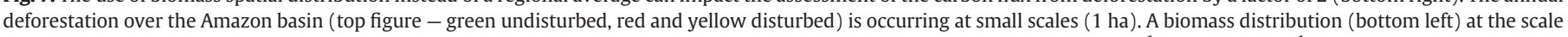

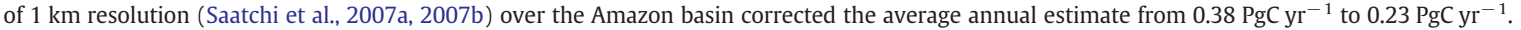


alone due to L-band radar saturation. In such cases, lidar sampling densities must be sufficient to achieve the required measurement accuracies, given the specifics of the instrument capabilities and mission parameters (orbit selection etc.). To meet the desired biomass measurement accuracy requirement implies sufficient numbers of lidar shots to estimate mean canopy height with 1 to $2 \mathrm{~m}$ accuracy within each grid cell. For a variety of biomes, populations of $1 \mathrm{~km}$ cells show a within-cell standard deviation of height that averages around $7 \mathrm{~m}$ but can range from about 3 to $15 \mathrm{~m}$ (see Fig. 6). Such variation implies that on average, 50 cloud-free lidar observations per $250 \mathrm{~m}$ grid cell would be required to achieve a height estimation accuracy of about $1 \mathrm{~m}$. A 5-beam lidar system in a proper orbit could over five years acquire this number of cloud-free shots at the equator (assuming 50\% data loss to cloud cover), hence meet the accuracy requirement at $250 \mathrm{~m}$ globally. After three years only three-fifths this number of samples would be available coarsening the spatial resolution of the lidar-only biomass maps by approximately $5 / 3$ at the same height accuracy.

There is a potential for fusion and geostatistical techniques to achieve the 1 to $2 \mathrm{~m}$ height accuracy at even smaller spatial resolutions in some regions. Furthermore, if an accuracy of $2 \mathrm{~m}$ was acceptable then it would lower the required number of shots to around 20 to achieve this accuracy at finer grid sizes. While it is desired to map biomass globally on a $100 \mathrm{~m}$ grid, the requirement specified is a $1 \mathrm{~km}$ grid spacing at the equator. Given the current lack of knowledge of biomass spatial distribution the required product would still represent a revolutionary leap in our ability to understand and model carbon changes in these areas.

3.1.2.5. For areas with carbon density $<40 \mathrm{MgC} \mathrm{ha}^{-1}$, global, spatially continuous biomass estimates at $100 \mathrm{~m}$ resolution, annually are required. Ecosystems with aboveground biomass of less than $40 \mathrm{MgC} \mathrm{ha}^{-1}$ include large regions of boreal forests of North America and Eurasia, tropical savanna woodlands, forest plantations and other less dense temperate forests, and young secondary forests (FAO, 2006; Goodale et al., 2002; Saugier et al., 2001). The capability of L-band radar to estimate biomass with the required 20\% accuracy in these regions has been demonstrated (Dobson et al., 1995; Kasischke et al., 1997; Luckman et al. 1997; Saatchi and Moghaddam 2000; Saatchi et al., 2007a, 2007b; Sun \& Ranson, 1995).

An important pol-SAR signal feature, and the basis for a global retrieval of forest biomass, is the stability of the biomass-backscatter relationship across this highly varied set of forest biomes. In addition to this intrinsic variability between backscatter and biomass there are extrinsic factors that can be minimized through proper instrument and spacecraft design and data processing; namely (1) variability in the backscattering coefficient resulting from radar speckle, (2) errors in the in-situ estimates of biomass, (3) geolocation errors and (4) radar spatial resolution.

However, L-band pol-SAR measurements at resolutions of approximately $10 \mathrm{~m}$ (single look) will be needed to provide the global pol-SAR coverage of vegetated areas providing about 100 looks within 1 ha grid cells. If necessary, to reduce the variability and improve pol-SAR calibration, the individual $10 \mathrm{~m}$ pol-SAR measurements can be aggregated to 250 or $500 \mathrm{~m}$ globally. Improved pol-SAR backscatter measurements at these larger spatial resolutions can be readily integrated with lidar samples for fusion approaches. There is ample research cited in the literature demonstrating that the $40 \mathrm{MgC} \mathrm{ha}^{-1}$ requirements can be met using L-band pol-SAR measurements (Dobson et al., 1995; Kasischke et al., 1997). In addition, multi-temporal measurements will reduce radar backscatter variability due to moisture and vegetation seasonality (Pulliainen et al., 1999). Furthermore, reducing the speckle noise by multi-look pol-SAR images will improve the calibration of the radar for separating biomass levels at larger spatial resolutions. Finally, low incidence angles improve penetration of pol-SAR waves into the

\section{Quality of fit using 25m footprint and existing slope correction technique (Lefsky et al. 2007)}
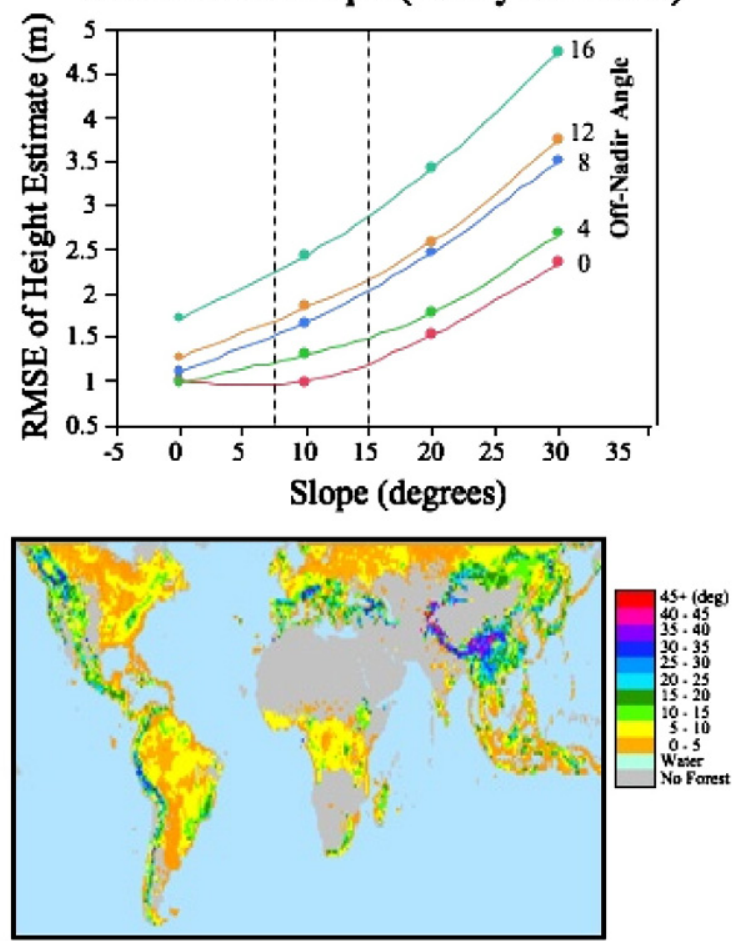

\section{Percent of forested land surface with $>7.5^{\circ}$ slope (SRTM-90)}

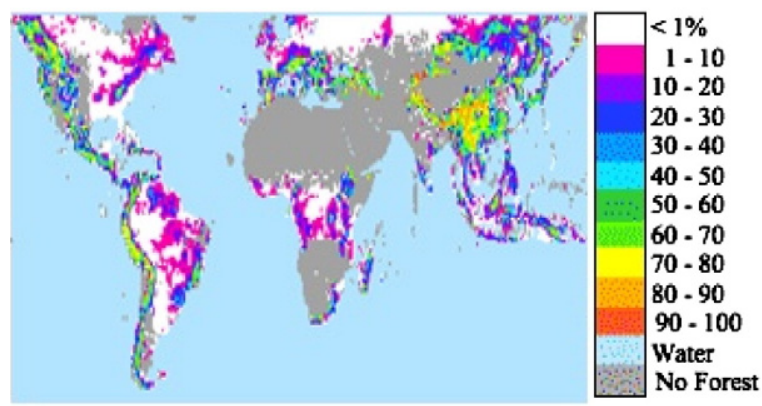

\section{Percent of forested land surface with $>15^{\circ}$ slope (SRTM-90)}

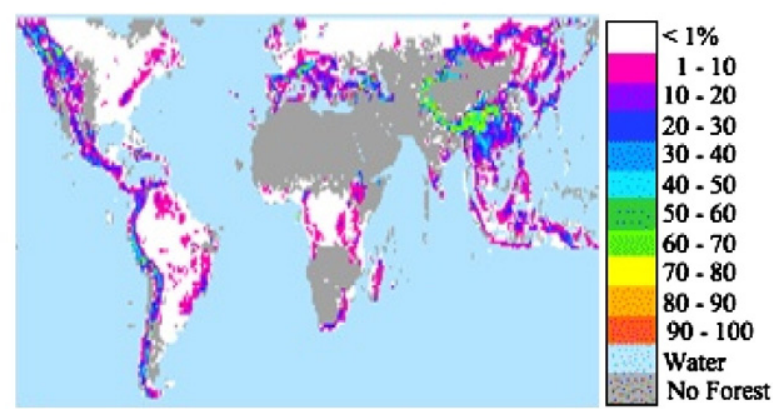

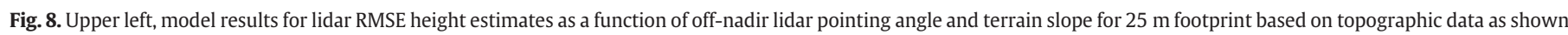
in remaining figures (Michael Lefsky, private communication). 
forest canopy and enhance the sensitivity to forest biomass. Incidence angles at about $30-35^{\circ}$ provide optimum penetration and polarization diversity to capture forest structure.

Seasonal coverage will also be necessary to reduce the variability associated with leaf-on, leaf-off periods for deciduous forests of northern hemisphere and savanna woodlands, and wet and dry seasons in tropical forests. At least two measurements to capture the extreme conditions will be sufficient to reduce the estimation error on a global scale.

3.1.2.6. Contiguously sampled profiles to estimate height correlation length scales (25 $\mathrm{m}$ and greater). The need for along-track contiguity of height measurements, i.e. transects, stems from several considerations, both ecological and technical, but it is driven primarily by the need to estimate the length scales of canopy variation to correctly observe the autocorrelation structure of the canopy (Shugart et al., 2000; Weishampel et al., 1992). Secondly, there are pragmatic considerations speaking for spatial continuity of lidar samples. Some shots will always be missed, either through clouds, dense canopy, etc. Isolated height samples are difficult to interpret without nearby shots, especially with regard to noise and ecosystem heterogeneity. This has been clearly demonstrated with ICESat data. Third, our ability to infer successional state of a stand is greatly facilitated by a contiguous sample of tree heights from which to infer the height distribution. This is quite difficult to do with non-contiguous samples, such as those shots from the ICESat GLAS laser, especially where forest patch sizes are relatively small. Finally, lidar canopy and height information from contiguous along-track samples, utilized in combination with pol-SAR images may be necessary to develop empirical and physically-based fusion algorithms, e.g. using Bayesian estimation where knowledge of canopy length scales and co-variation with canopy, topographic and pol-SAR backscatter correlates are required.

\subsection{Biomass change and carbon flux}

Disturbance from fire, logging, insects, wind damage etc. creates carbon flux to the atmosphere. Recovery following disturbance reabsorbs carbon from the atmosphere. The balance of these two processes at landscape scales dominates the interannual land-atmosphere carbon exchange. Eq. (4) identifies a number of measurement and modeling needs to obtain the information for assessing the terrestrial carbon balance and prognosticating future trends. The $\Delta \mathrm{C}$ terms in Eq. (4) can be measured using the difference between the initial biomass inventory data and the biomass following disturbance. If the mission meets the needs specified in Section 3.1 for biomass, the only new information needed is identification, location and mensuration of all disturbed patches (Masek et al., 2008), and new measures of biomass for each patch. The gain in biomass from recovery in Eq. (4) can be measured directly by differencing subsequent biomass measures provided the mission lifetime is long enough. In any case, modeling will be needed to supplement direct measurements to estimate the NEP terms in Eq. (4) and prognosticate their dependence on future climate scenarios. We will summarize in Section 3.2.1 separately, the needs for measuring disturbance, and measuring and/or modeling recovery rates.

\subsubsection{Summary of core observables}

3.2.1.1. The core observables for biomass loss are changes in biomass from disturbance. The desired spatial resolution for disturbance is 1 ha, with sufficient accuracy to detect a biomass loss of $50 \%$ or at worst, disturbances resulting in a $90 \%$ loss. The required spatial resolution is $1 \mathrm{~km}$. For areas of more subtle disturbance (selective logging, tree fall and mortality) with losses less than $50 \%$, the spatial resolution may need to be coarsened to $1 \mathrm{~km}$ to acquire the $>1000$ looks needed to reduce pol-SAR noise. Using lidar/pol-SAR fusion it may be possible to achieve desired accuracies with fewer looks. For low biomass areas, estimates of interannual changes satisfying accuracy requirements can potentially be made at the finer resolution of $500 \mathrm{~m}$.
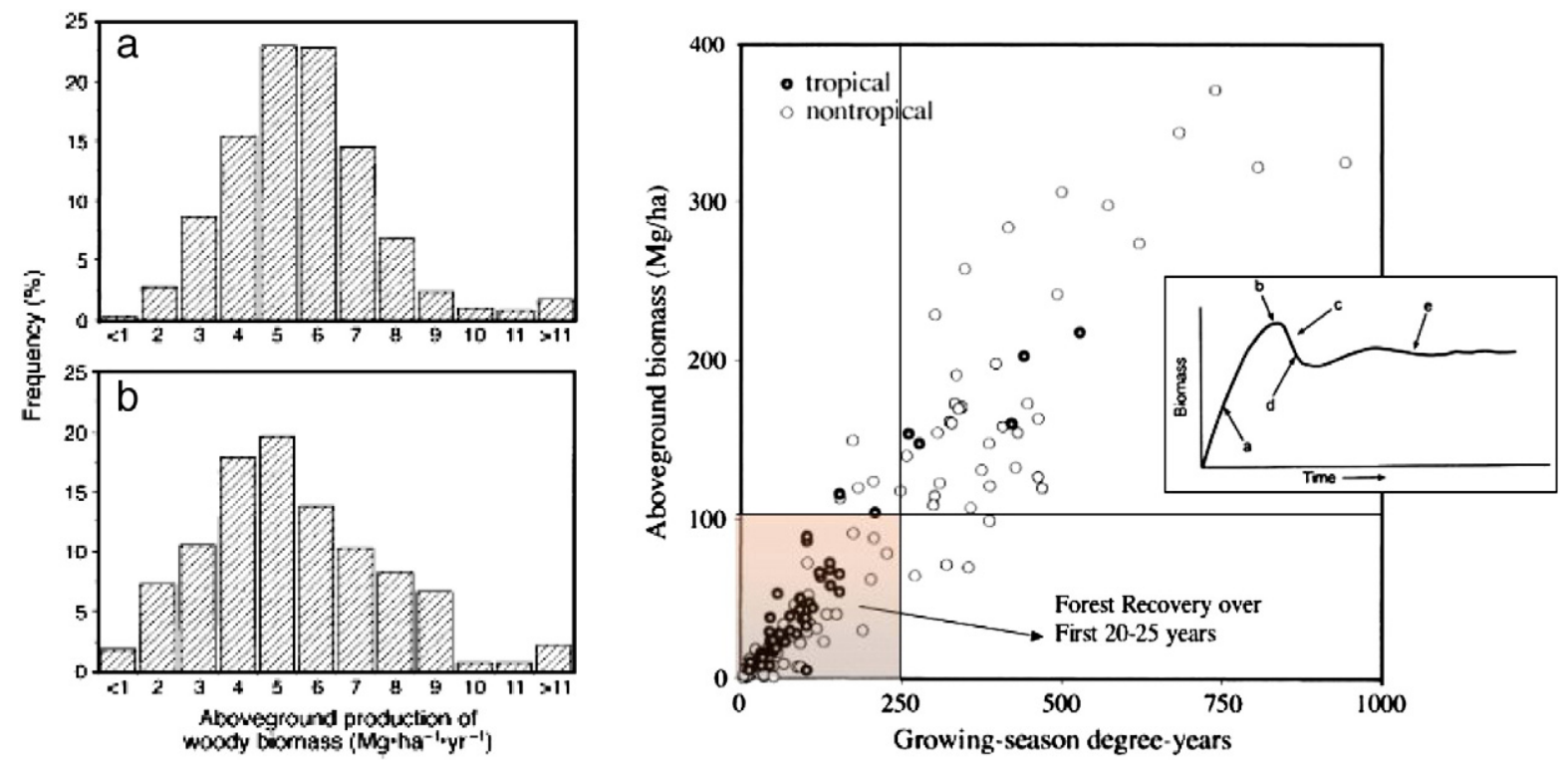

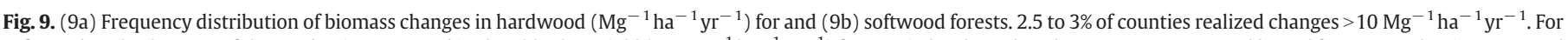

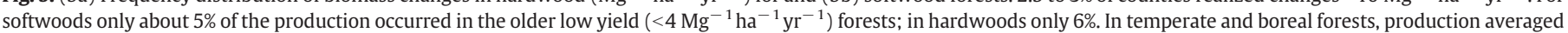

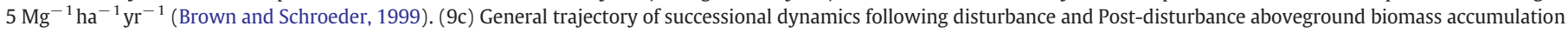

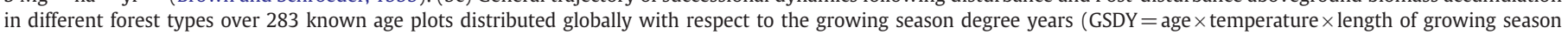
divided by 365 days). GSDY of 250 is approximately equivalent of 20-25 yrs of forest age (Johnson et al., 2001). 
3.2.1.2. The core observables from biomass gain from recovery are changes in biomass. The desired accuracy is to quantify a biomass gain of 2$10 \mathrm{MgC} \mathrm{ha}{ }^{-1}$ at 1 ha grid spacing on an interannual basis. The required spatial resolution for low biomass areas is $1 \mathrm{~km}$, but again identifying disturbance and recovery after disturbance at $100 \mathrm{~m}$ resolution (Table 2). Rates of biomass development in young forests are much faster than the old-growth forests with biomass staying below $100 \mathrm{Mg} \mathrm{ha}^{-1}$ for the first 10-20 yrs after disturbance (Chazdon, 2003; Johnson et al., 2001). As seen from Fig. 9a increases in woody biomass in soft and hardwoods varied from 2 to more than $11 \mathrm{Mg} \mathrm{ha}^{-1} \mathrm{yr}^{-1}$. For softwoods only about $5 \%$ of the production occurred in the older low yield $\left(<4 \mathrm{Mg} \mathrm{ha}^{-1} \mathrm{yr}^{-1}\right)$ forests, in hardwoods only 6\%. Forest inventories in the U.S. suggest that an accuracy of $2 \mathrm{Mg} \mathrm{ha}^{-1} \mathrm{yr}^{-1}$ would capture the growth of more than $90 \%$ of the counties in the eastern U.S. (Brown and Schroeder, 1999).

\subsubsection{Required biomass change measurement capabilities}

3.2.2.1. Global coverage of forested areas. At least two global maps are desired yearly to capture seasonally variability, to map the disturbance and to measure the biomass change on an annual cycle. The products will be improved over areas using lidar/radar fusion methods with more frequent pol-SAR measurements or higher numbers of lidar samples. Seasonal measurements are performed during the leaf-on and leaf-off periods (early and later growing seasons) in northern mid and high latitude forests and the peak of wet and dry seasons in the tropics (see Fig. 10). As far as pol-SAR measurements are concerned, it is preferable to avoid winters of high latitude vegetated areas because of increasing

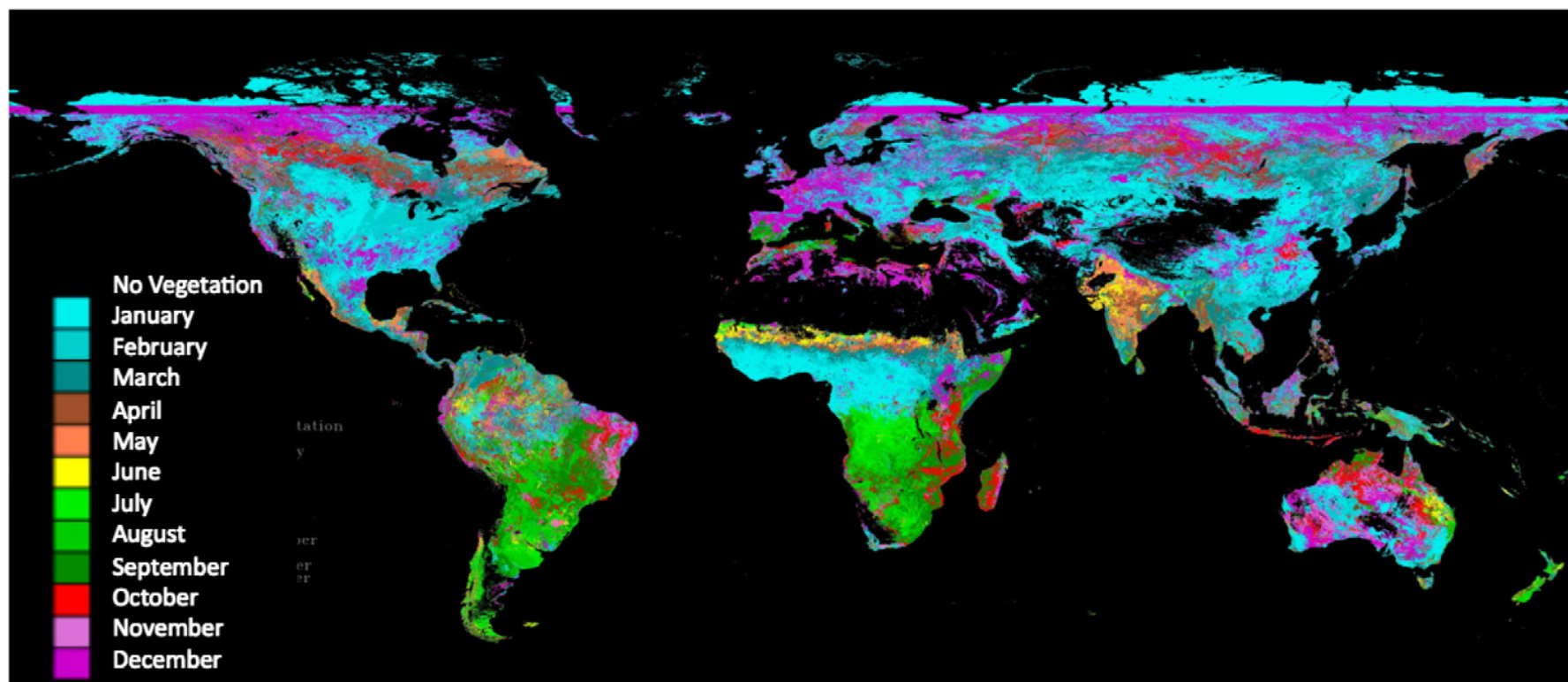

\section{Minimum Vegetation}

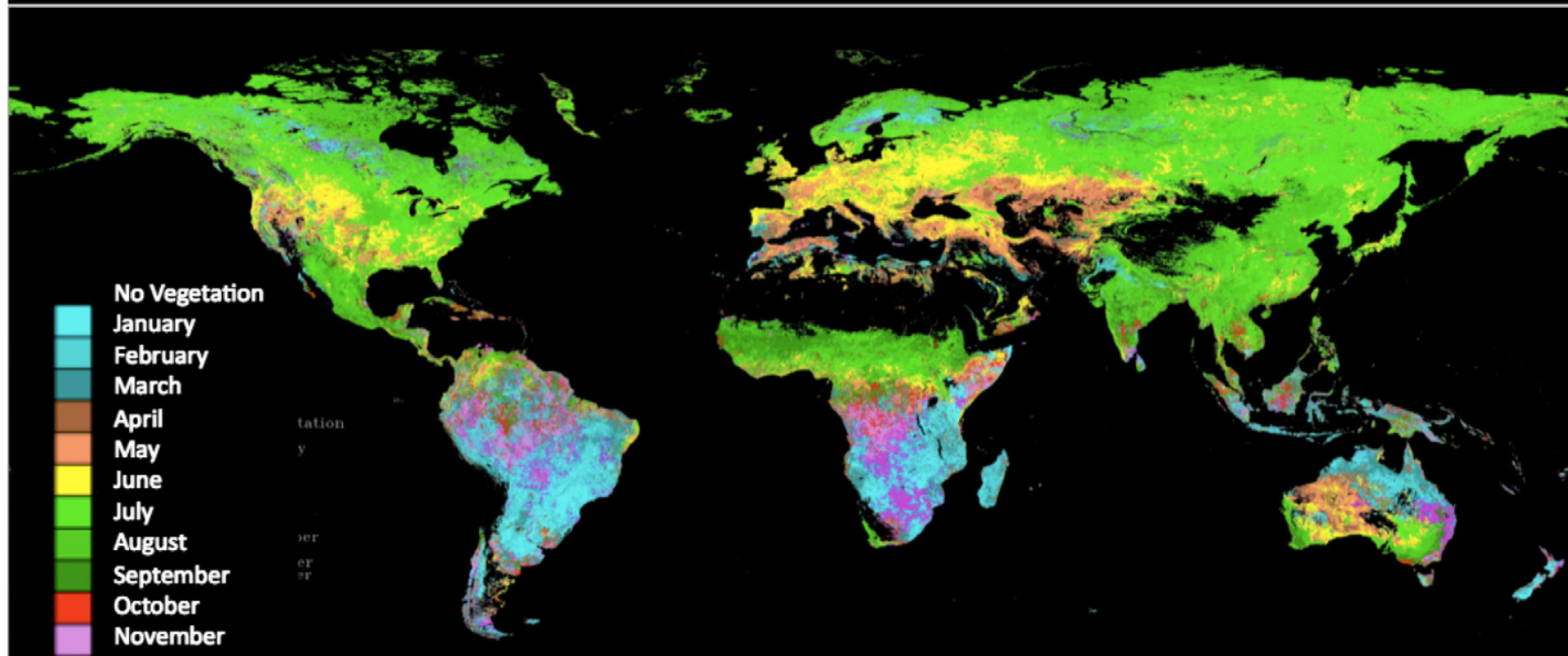

December

\section{Maximum Vegetation}


effect of snow and freezing condition. For lidar measurements of annual change, peak leaf on period is necessary for year-to-year consistency. In the boreal ecosystem this is about a three-month period; for the tropics, much longer (6-12 months).

3.2.2.2. Targeted response for events (hurricanes, fire, blow downs). This has the same justification as for disturbance; however, the targeted aspect is related to a mission requirement, i.e. the need to obtain high-resolution pol-SAR imagery in a reasonable time after the disturbance event. 3.2.2.3. Spatial resolution. One hectare spatial resolution requires $100,10 \mathrm{~m}$ single pol-SAR looks. Large disturbance events need to be mapped at this resolution globally at least twice a year. Over environmentally heterogeneous landscapes, the required spatial resolution for inputs to biomass and biomass change modeling may drive mission requirements. Recent studies using forest dynamics computer simulation models suggest that models initialized with data that is too coarse to resolve the distribution in vegetation height (and how it is correlated to underlying environmental gradients) incur substantial initialization and flux prediction error. Operationally, model prediction errors over complex mountainous terrain increase rapidly at data scales $>1$ ha (Hurtt et al., 2010; Thomas et al., 2008).

3.2.2.4. Temporal resolution. For periodic biomass surveys, intervals less than a year are generally too short for accurate measurement of most changes in biomass. Intervals greater than a year can miss an opportunity to attribute year-to-year variations in carbon emissions to disturbance, as opposed to metabolism (photosynthesis and respiration). Ecological processes functioning at various spatial and temporal scales add to the complexity and variability of carbon dynamics of vegetated ecosystems (see Fig. 11). An annual measurement of changes in biomass at high spatial resolution will enable the processes contributing to that variation (fire or respiration) to be quantified.

Biomass changes can be inferred either by differencing direct subsequent biomass inventories or using biomass estimation algorithms employing temporal differences of pol-SAR and lidar signals to infer structure and biomass change from two or more pol-SAR/lidar acquisitions. If inferred by differencing subsequent radar biomass inventories, the accuracy of $\pm 20 \%$ in each of two biomass inventories in different years could map global areas of disturbance and regrowth at 1 ha resolution annually with regrowth to an accuracy of $4 \mathrm{Mg} \mathrm{ha}^{-1} \mathrm{yr}^{-1}$ for areas disturbed at least 4 yrs prior to the first observation and where the resulting biomass was less than $80 \mathrm{Mg} \mathrm{ha}^{-1}$. With a three-year mission an accuracy of $\sim 7 \mathrm{Mg} \mathrm{ha}^{-1} \mathrm{yr}^{-1}$ would be feasible.

3.2.2.5. Minimum 5-year observation period for chronosequencing and successional state. A minimum of 5 yrs of annual observations of forest structure is needed to establish the composition and structure of a patch recovering from disturbance. The successional dynamics will depend both on the type of disturbance and the pre-disturbance forest, as well as post-disturbance recovery and management techniques. As forest patches recover from disturbance, a pattern of succession unfolds, beginning with pioneer species that initially colonize the disturbed patch, followed by early successional species that eventually become the canopy dominants. Seasonal to annual measurements over a minimum of 5 yrs will allow us to identify this trajectory. In addition, by improving the estimation of forest biomass over 5 yrs of lidar and pol-SAR data acquisition, we will be able to map forests at different stages of successions. In summary, the two products aboveground biomass map and biomass change will capture the successional state and the rate of succession, and the underlying mechanism of successional trajectory as shown in Fig. 9b. The occurrence of such patterns has been documented for several different mature forest systems and is consistent with the mosaic dynamics of mature forests (Hartshorn, 1978; Knight, 1975; Oliver, 1980; Raup, 1964; White, 1979; Whitmore, 1974).

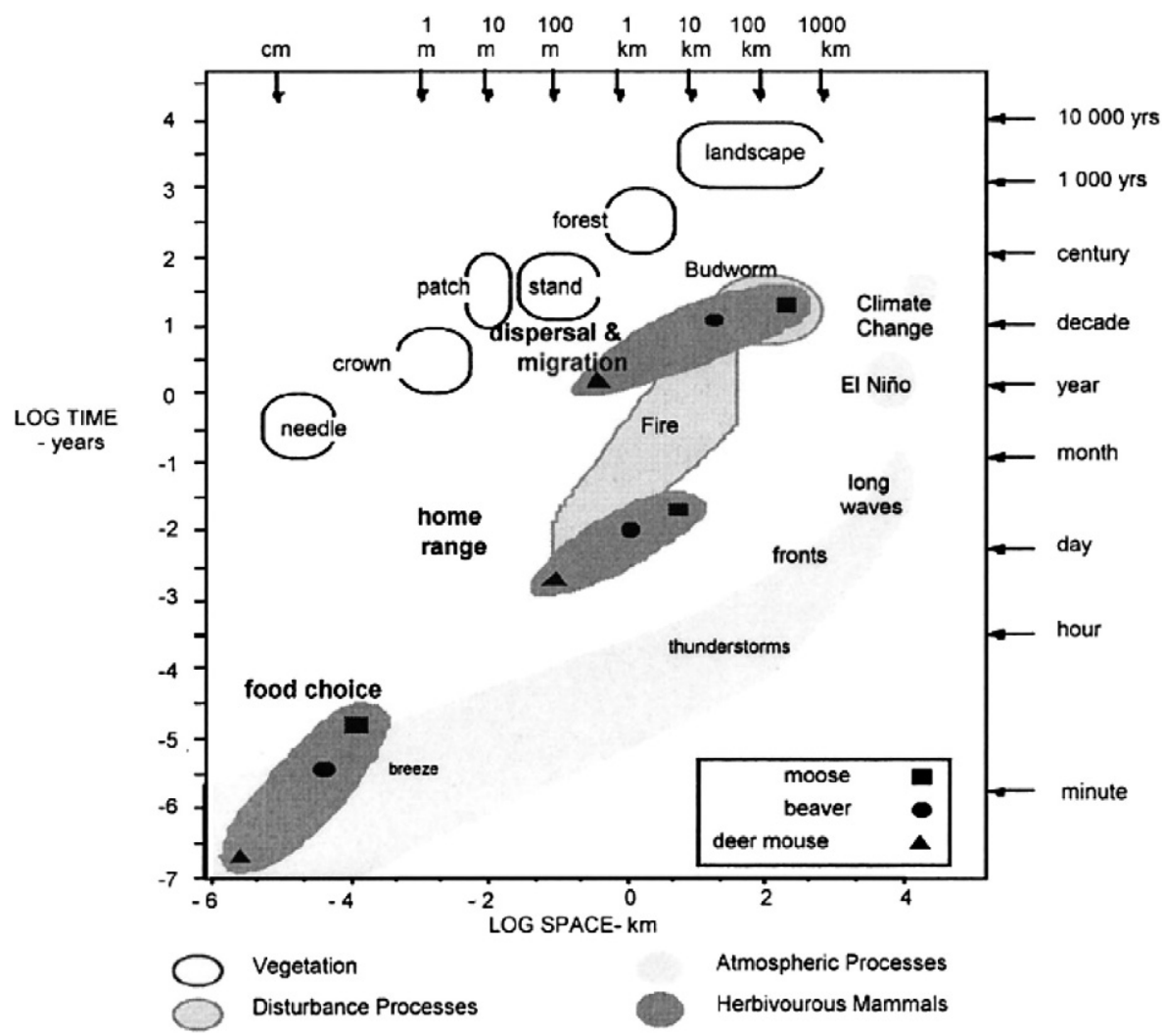

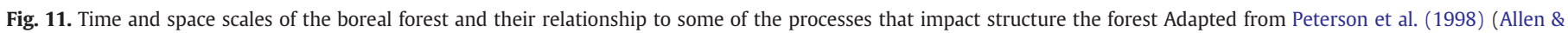
Hoekstra, 1992). 
Table 3

Biodiversity/habitat measurement goals and requirements.

\begin{tabular}{|c|c|c|}
\hline Measurement goals/requirements & Justification/rationale & Verification method \\
\hline $\begin{array}{l}\text { Habitat structure: transects of vegetation vertical canopy profiles } \\
\text { over all biomes at } 25 \mathrm{~m} \text { spatial resolution, } 30 \mathrm{~m} \text { along-transect } \\
\text { posting, with a maximum of } 250 / 500 \mathrm{~m} \text { across-transect posting at } \\
\text { end of mission and } 1 \mathrm{~m} \text { vertical resolution up to conditions of } 99 \% \\
\text { canopy cover. (Biomass and biomass change requirements are } \\
\text { identical to those above). }\end{array}$ & $\begin{array}{l}\text { Global characterization of habitat structure is critical to improving } \\
\text { information on the relationship of 3D forest structure and change } \\
\text { to biodiversity and biodiversity change. }\end{array}$ & $\begin{array}{l}\text { Geolocate observations over } \\
\text { reference surfaces and determine } \\
\text { spatial distribution and resolutions }\end{array}$ \\
\hline
\end{tabular}

\subsection{Biodiversity and habitat measurement requirements}

\subsubsection{Summary of core observables}

3.3.1.1. The core observational requirement is to characterize forest structure and biomass for habitat and biodiversity assessments. Habitat and biodiversity studies require fine resolution measurements of vegetation vertical structure and biomass at both the pixel level and over contiguous domains in landscapes. Organisms and local populations typically discriminate suitable habitat at fine resolutions at landscape scales; therefore vegetation measurements are required at commensurate resolutions and extents. Global-to-regional habitat and biodiversity patterns are controlled by climate (Wright, 1983) and over landscapes at regional scales by topography (Burnett et al., 1998). Analysis and interpretation of global-to-regional habitat and biodiversity patterns may also benefit, in ways not yet well understood, from $1 \mathrm{ha}$ to $1 \mathrm{~km}$ resolution global vegetation structure and biomass products (as discussed in Section 2.1 for biomass).

In terms of the general precision of vegetation structure and biomass estimates, sparse forests and shrublands (vegetation less than about $5 \mathrm{~m}$ tall) are important habitats for many species. Therefore, the Lidar should be designed to ensure that height measures are accurate to within 1$2 \mathrm{~m}$. With respect to the pol-SAR, cross-polarization has been shown to be useful in crown cover and biomass retrievals, and therefore crosspolarization is a minimum requirement for the pol-SAR. Because of the need to map habitat contiguously (rather than to sample), wall-to-wall coverage is required; thus the fusion of lidar plots and transects with pol-SAR will be important. Because edges and patch sizes are important to many species and to patterns of diversity, contiguous along-track lidar plots are highly desired. Following are more specific required measurement capabilities. See Table 3 for a summary of biodiversity and habitat measurement requirements.

\subsubsection{Required measurement capabilities for habitat and biodiversity}

Measurements characterizing vegetation vertical structure and biomass, landscape horizontal structure and biomass and landscape heterogeneity are needed to fully characterize vegetated areas for habitat and biodiversity. The following variables and characteristics are seen as both important and feasible to derive from pol-SAR, InSAR and lidar sensors.

3.3.2.1. Global coverage of forested ecosystems. Vegetation and landscape structures, indispensible as habitat for biodiversity, are rapidly changing worldwide due to human- and nature-driven land-cover change. Implications for the Earth's biodiversity include loss of habitat, increasing extinctions, invasive species and alteration of ecosystem functioning (Sala et al., 2000). DESDynI will need to establish complete coverage of Earth's 3D vegetation structure and biomass as a scientific baseline in order to enable quantification of change and of trends in habitat and biodiversity. In addition, while some forested ecosystems are "hotspots" for habitat degradation as a result of changing land use patterns, the locations of such changes are distributed over the globe (Brooks et al., 2006), and in some cases unknown from lack of observation. Data from all areas of the globe supporting woody vegetation (Fig. 3) will be required in order to assess the global extent of threats to biodiversity and habitat and in order to observe the different geographic areas perceived as priorities for conservation (Brooks et al., 2006; Lee \& Jetz, 2008; Wilson et al., 2006). The global perspective makes demands on the sensor temporal configurations, especially as related to tree phenology in different biomes (Fig. 10). While tropical moist forest biomes at low latitudes exhibit lower seasonality but may be asynchronous in timings of leaf phenology, other biomes especially temperate forests at higher latitudes, have strong and seasonalities and synchronous phenology. Given seasonal considerations, leaf-on is required for the lidar in all biomes and a temporal resolution of 90 days between pol-SAR repeat coverage would be optimal, but 180 days would be acceptable. Orbit design should consider interactions between regional and seasonal variations in cloud cover (Fig. 12) and phenology to maximize lidar acquisition probabilities during leaf-on.

3.3.2.2. Targeted response for events (hurricanes, fire, blow downs, insects, etc.). Periodic or stochastic disturbance events such as hurricanes, other wind blow downs, fire and insects can have significant impacts on vegetation 3D structure and consequently on biodiversity and habitat of plants and animals (Spies \& Turner, 1999). To understand the implications of such events for species habitats, high-resolution pol-SAR imagery of such areas is needed soon after the event in a time fame prior to significant recovery. Thus radar and lidar targeting capability should be a mission requirement, consistent with the requirement for observing changes in biomass following such events.

3.3.2.3. Canopy cover, $\pm 10 \%$ at $25 \mathrm{~m}$ resolution, leaf-on, same season each year. Measuring canopy cover to $\pm 10 \%$ is both feasible and necessary for biodiversity assessments (Hyde et al., 2006). Canopy cover observations must be taken when leaves are present and made during at the same vegetation phenology each year (Fig. 10). Accurate canopy cover measurements from lidar are sensitive to slope effects, and a 25 -m footprint is the maximum acceptable for biodiversity studies. SARs have also been shown to be indirectly sensitive to degree of canopy cover (Green, 1998), however repeated precisions are not known and fusion with lidar and/or passive optical sensors needs to be more thoroughly explored for wall-to-wall mapping of canopy cover.

3.3.2.4. Canopy height ( $\pm 2 \mathrm{~m}, 1 \mathrm{~m}$ desired), annually, same season, contiguously sampled profiles to estimate height correlation length scales (25 $\mathrm{m}$ and greater). As discussed in Section 2.1.2, forest height (or canopy height) has been correlated with suitability of habitat for species of birds, mammals and other taxa, and used as a management tool for biodiversity planning. A number of lidar metrics relate to canopy height within a stand; maximum canopy height (first-last return height), height of median energy (HOME), and other quantile height distributions are important for habitat and biodiversity studies. A lidar-derived absolute canopy height precision (repeatability of lidar metrics for a cross-over pixel) of $\pm 2 \mathrm{~m}$ is required, and $\pm 1 \mathrm{~m}$ is desired, especially to accurately represent young forest or shrub vegetation, where an absolute error of $\pm 1 \mathrm{~m}$, may represent an undesirably high relative error. 


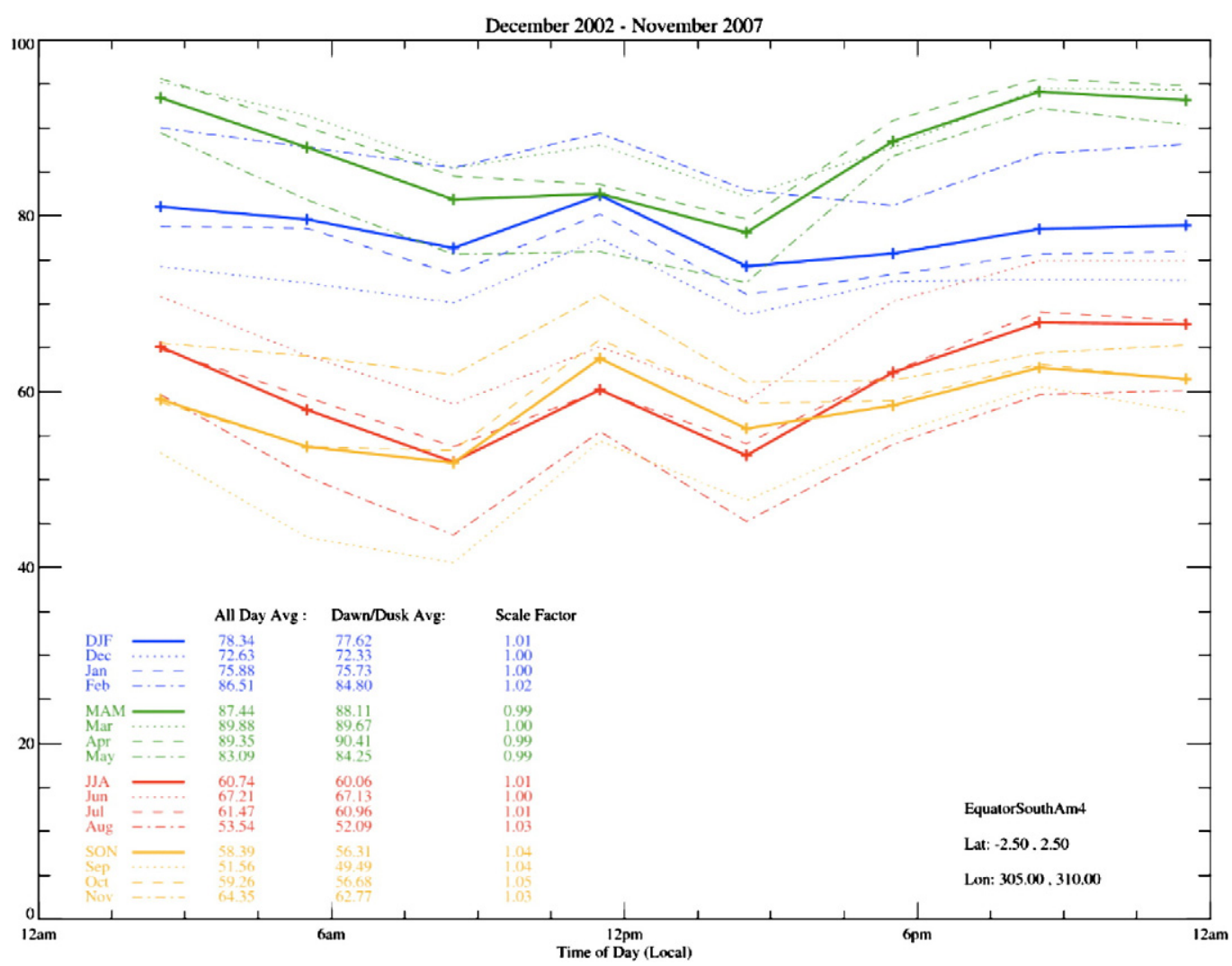

Fig. 12. ISCCP cloud cover probabilities (3 hourly) for Equatorial South America, showing some diurnal variation and strong seasonal variation.

3.3.2.5. Canopy height profile, lidar $1 \mathrm{~m}$ quantile heights, with a within-canopy relative accuracy of $\pm 5 \%$ (under $99 \%$ or greater canopy cover and on flat terrain);25 m resolution, contiguous, leaf-on, annual, same season each year. As discussed in Section 1.2.3, vertical profiles of canopy structure are essential for measuring the vertical distribution of vegetation in a canopy. Canopy height profiles make possible the study of individual layers through quantile heights that are desired in $1 \mathrm{~m}$ lidar bins. For the canopy height profiles, a lidar vertical resolution of $\pm 2 \mathrm{~m}$ would be required, and $\pm 1 \mathrm{~m}$ is desired. Desired footprint size is again $25 \mathrm{~m}$ resolution, with observations taken annually and during the same leaf-on season each year.

3.3.2.6. Biomass at nominal $30 \mathrm{~m}$ radar pixel spatial resolutions for local applications; for global products as in Section 1.2 .2 at $250 \mathrm{~m}$ resolution after 5 yrs of observations and at $100 \mathrm{~m}$ for low biomass areas. Because of the fragmented and variable nature of many regional landscapes, we suggest a polSAR spatial resolution no coarser than $30 \mathrm{~m}$ in order to meet biodiversity and habitat needs over such heterogeneous landscapes. At the regional to global scales, the biomass measurement requirements for biodiversity are the same as the requirements for the coarser biomass science product proposed (this paper, Section 2.1). At local to landscape scales, accurate fine scale field or other calibration data may be used to help achieve these accuracies and to map biomass at 1-ha or finer scales.

\section{Conclusions}

There are pressing needs to rapidly advance our understanding of how changes in the 3D structure of terrestrial vegetation is affecting the global carbon cycle and the habitability and sustainability of those ecosystems. Uncertainties in the amount, location and rate of change in the Earth's vegetation biomass are the largest contributor to uncertainty in future atmospheric $\mathrm{CO}_{2}$ concentrations, hence climate change. These uncertainties also feed into uncertainties about the future suitability of terrestrial ecosystems to sustain the life fundamentally dependent upon them.

Vegetation structural information is currently available only over very limited regional scales. But these local studies have clearly demonstrated the potential at a global scale of vegetation 3D information to revolutionize our understanding of the key roles that the Earth's vegetation and its changes over time plays in the global carbon cycle, climate, and ecosystem habitability.

New space assets are urgently needed to measure the 3D structure of global vegetation and its changes at annual time scales at high spatial resolution.
- The lidar and mission orbit design should be capable of measuring global biomass with accuracies of $20 \%$ (error magnitude between 10 and $25 \mathrm{MgC} \mathrm{ha}^{-1}$ ), for $90 \%$ of forested grid cells of $1 \mathrm{~km}$ spatial resolution. For forested areas of low biomass $\left(<40 \mathrm{MgC} \mathrm{ha}^{-1}\right)$ the lidar and radar and mission design should be capable of increasing the spatial resolution of the biomass products to $100 \mathrm{~m}$. Fusion of the radar and lidar products have shown potential to further increase the spatial resolution of the biomass product at all biomass levels, perhaps to $250 \mathrm{~m}$.

- Radar can be used to map disturbance in areas 1 ha or greater for which biomass decreases by $50 \%$ or more.

- The mission should be able to produce estimates of average biomass increase with an accuracy of $2 \mathrm{MgC} \mathrm{ha}^{-1} \mathrm{yr}^{-1}$ for patches with biomass $\leq 40 \mathrm{MgC} \mathrm{ha}^{-1}$ after observation for a period of $4 \mathrm{yrs}$ or more. For mission lifetimes of 2 yrs or less biomass change products will be limited to disturbance maps and modeled biomass change.

- Them mission should be capable of producing transect maps of vertical forest canopy profiles and structure consisting of $30 \mathrm{~m}$ along-transect measurements at $25 \mathrm{~m}$ spatial resolution, with transects separated by $250 \mathrm{~m}$ or less in canopy cover up to $98 \%$. 
Combined radar and lidar instruments in space, can produce 3D global forest structure information not previously available that will significantly advance our understanding of terrestrial carbon dynamics and their implications for climate change.

Sufficiently high lidar sampling density and fusion with radar are required to establish the initial global data record of biomass and habitability at the required accuracy and resolution. A two-year mission could, with sufficient numbers of lidar samples and fusion provide biomass and habitability information satisfying the information needs. But landscape disturbance and regrowth rates of $4 \mathrm{Mg} \mathrm{ha}^{-1} \mathrm{yr}^{-1}$ would need to be observed for at least 5 yrs to be measureable with biomass accuracies of $10 \mathrm{MgC} \mathrm{ha}^{-1}$.

The technology readiness levels of combined pol-SAR and lidar instruments are adequate to render the global 3D structural information products necessary to produce high resolution biomass, biomass change and the vegetation structural maps to support carbon cycle, biodiversity and habitability studies. L-band quadpol pol-SAR imagery combined with lidar profile samples of the earth's vegetation at a suitably high density have been shown adequate to measure biomass with the required precision over a large majority of even the more densely forested canopies. pol-SAR will provide frequent coverage of disturbance, even in tropical cloud covered areas where changes resulting from land use are the most rapid and most uncertain. Remaining to be worked out, are the particulars of a lidar/pol-SAR mission design that meet these ecosystem structure requirements.

\section{Acknowledgements}

The authors would like to acknowledge the many scientists who contributed their time and energy to this study, particularly by their attendance at the Charlottesville, Va. workshop, March 3-5, 2008. The workshop developed much of the material in this paper. Also, we express our appreciation to the various scientists who have participated in regular teleconferences to iterate and clarify the rationale underlying the measurement requirements. The principal author would be remiss in not highlighting his role in this overview paper, to incorporate the expert knowledge of his co-authors, listed alphabetically, into an integrated whole. Dr. Ralph Dubayah served as the DESDynI science team ecosystem lead spearheading the development of the instrument and science requirements reported in this paper. Finally, the co-authors thank the anonymous reviewers who carefully scrutinized this manuscript on two occasions and provided invaluable comments and suggestions for its improvement.

\section{References}

Achard, F., Eva, H. D., Stibig, H. -J., Mayaux, P., Gallego, J., Richards, T., et al. (2002). Determination of deforestation rates of the world's humid tropical forests. Science, 297, 999-1002.

Allen, T. F. H., \& Hoekstra, T. W. (1992). Toward a unified ecology. New York: Columbia University Press.

Anderson, S. H., \& Shugart, H. H. (1974). Habitat selection of breeding birds in an east Tennessee deciduous forest. Ecology, 55, 828-837.

Angelsen, A., Brown, S., Loisel, C., Peskett, L., Streck, C., \& Zarin, D. (2009). Reducing Emissions from Deforestation and Forest Degradation (REDD): An options assessment report. Washington, DC: Meridian Institute.

Baccini, A., Friedl, M. A., Woodcock, C. E., \& Warbington, R. (2004). Forest biomass estimation over regional scales using multisource data. Geophysical Research Letters, 31, L10501. doi:10.1029/2004GL019782.

Bergen, K. M., Gilboy, A. M., \& Brown, D. G. (2007). Multi-dimensional vegetation structure in modeling avian habitat. Ecological Informatics, 2(1), 9-22.

Bergen, K., Goetz, S., Dubayah, R., Henebry, G., Hunsaker, C., Imhoff, G., et al. (2009). Remote sensing of vegetation 3D structure for biodiversity and habitat: Review and implications for lidar and radar spaceborne missions. Journal of Geophysical Research, 114(G00E06). doi:10.1029/2008JG000883.

Bergen, K., Knox, R., \& Saatchi, S. (Eds.). (2005). Multi-dimensional forested ecosystem structure: Requirements for remote sensing observations. Final report of the NASA Workshop held June 23-25 2003, Annapolis, MD. NASA GSFC Report NASA/CP-2005-212778.

Bounoua, L., Collatz, G. J., Los, S., Sellers, P. J., Dazlich, D. A., Tucker, C. J., et al. (2000). Sensitivity of climate to changes in NDVI. J. Climate, 13, 2277.
Bounoua, L., Hall, F. G., Sellers, P. J., Kumar, A., Collatz, G. J., Tucker, C. J., et al. (2010). Quantifying the negative feedback of vegetation to greenhouse warming. A modeling approach. Geophys. Res. Lett, 37, 1-5.

Brown, S. L., \& Schroeder, P. (1999). Spatial distribution of biomass in forests of the eastern USA. For. Ecol. Manage., 123, 81-90.

Brokaw, N., \& Lent, R. (1999). Vertical structure. In M. Hunter (Ed.), Maintaining biodiversity in forest ecosystems (pp. 373-399). Cambridge: Cambridge University Press.

Brooks, T. M., Mittermeier, R., da Fonseca, G. A. B., Gerlach, J., Hoffmann, M., Lamoreux J., et al. (2006). Global biodiversity conservation priorities. Science, 313, 58-61.

Brown, S., Iverson, L. R., Prasad, A., \& Liu, D. (1993). Geographical distributions of carbon in biomass and soils of tropical Asian forests. Geocarto International, 8, 45-59.

Brown, S., \& Lugo, A. E. (1992). Aboveground biomass estimates for tropical moist forests of the Brazilian Amazon. Interciencia, 17, 8-18.

Brown, S. J., \& Schroeder, P. E. (1999). Spatial patterns of aboveground production and mortality of woody biomass for eastern US forests. Ecol. Appl., 9, 968-980.

Burnett, M. R., August, P. V., Brown, J. H., Jr., \& Killingbeck, K. T. (1998). The influence of geomorphological heterogeneity on biodiversity: I. A patch-scale perspective. Conservation Biology, 12, 363-370.

Butchart, Stuart H. M., Walpole, Matt, Collen, Ben, van Strien, Arco, Scharlemann, Jörn P. W. Almond, Rosamunde E. A., et al. (2010). Global biodiversity: Indicators of recent declines. Science, 328, 1164-1168.

Cairns, M. A., Brown, S., Helmer, E. H., \& Baumgardner, G. A. (1997). Root biomass allocation in the world's upland forests. Oecologia, 111, 1-11.

Canadell, J. G., Le Quéré, C., Raupach, M. R., Field, C. B., Buitenhuis, E. T., Ciais, P., et al. (2007). Contributions to accelerating atmospheric $\mathrm{CO}_{2}$ growth from economic activity, carbon intensity, and efficiency of natural sinks. Proceedings of the National Academy of Sciences, 104, 18866-18870.

Chave, J., Condit, R., Aguilar, S., Hernandez, A., Lao, S., \& Perez, R. (2004). Error propagation and scaling for tropical forest biomass. Phil. Trans. R. Soc. B., 359, 409-420.

Chazdon, R. L. (2003). Tropical forest recovery: Legacies of human impact and natura disturbances. Perspectives in Plant Ecology, Evolution and Systematics, 6, 51-71.

Cloude, S. R., \& Papathanassiou, K. P. (1998). Polarimetric SAR interferometry. IEEE Trans. Geoscience and Remote Sensing, 36, 1551-1565.

Conradsen, K. A. A., Nielsen, J. Schou, \& Skriver, H. (2003). A test statistic in the complex Wishart distribution and its application to change detection in polarimetric SAR data. IEEE Trans. Geosci. Remote Sensing, 41(1), 4-19.

Couturier, S., Taylor, D., Siegert, F., Hoffmann, A., \& Bao, M. Q. (2001). ERS SAR backscatter-A potential real-time indicator of the proneness of modified rainforests to fire. Remote Sensing of the Environment, 76, 410-417.

Davidson, E. A., \& Janssens, I. A. (2006). Temperature sensitivity of soil carbon decomposition and feedbacks to climate change. Nature, 440, 165-173. doi:10.1038/ nature04514.

DeFries, R., Achard, F., Brown, S., Herold, M., Murdiyarso, D., Schlamadinger, B., et al. (2007). Earth observations for estimating greenhouse gas emissions from deforestation in developing countries. Environmental Science and Policy, 10, 385-394.

DeFries, R. S., Houghton, R. A., Hansen, M. C., Field, C. B., Skole, D., \& Townshend, J. (2002). Carbon emissions from tropical deforestation and regrowth based on satellite observations for the $1980 \mathrm{~s}$ and 90 s. Proceedings of the National Academy of Sciences, 99, 14256-14261.

Denman, K. L., Brasseur, G., Chidthaisong, A., Ciais, P., Cox, P. M., Dickinson, R. E., et al (2007a). Couplings between changes in the climate system and biogeochemistry. In S. Solomon, D. Oin, M. Manning Z. Chen, M. Marquis, K. B. Averyt, M. Tignor, \& H. L. Miller (Eds.), Climate Change 2007: The Physical Science Basis. Contribution of Working Group 1 to the Fourth Assessment Report of the Intergovernmental Panel on Climate Change (pp. 499-587). Cambridge, UK and New York, NY, USA: Cambridge University Press.

Denman, K. L., et al. (2007b). Couplings between changes in the climate system and biogeochemistry. In S. Solomon (Ed.), Climate Change 2007: The Physical Science Basis. Contribution of Working Group 1 to the Fourth Assessment Report of the Intergovernmental Panel on Climate Change (pp. 499-587). New York: Cambridge Univ. Press.

Dobson, M. C., Ulaby, F. T., Pierce, L. E., Sharik, T. L., Bergen, K. M., Kellndorfer, J., et al (1995). Estimation of forest biophysical characteristics in Northern Michigan with Sir-C/X-SAR. IEEE Transactions on Geoscience and Remote Sensing, 33, 877-895.

Drake, J. B., Knox, R., Dubayah, R., Clark, D., Condit, R., \& Blair, J. (2003). Aboveground biomass estimation in closed-canopy Neotropical forests using LiDAR remote sensing: Factors affecting generality of relationships. Global Ecology and Biogeography, 12(2), 147-159.

Drake, J. B., Dubayah, R. O., Knox, R. G., Clark, D. B., \& Blair, J. B. (2002a). Sensitivity of large-footprint lidar to canopy structure and biomass in a neotropical rainforest Remote Sensing of Environment, 81, 378-392.

Drake, J. B., Dubayah, R. O., Clark, D. B., Knox, R. G., Blair, J. B., Hofton, M. A., Chazdon, R. L., Weishampel, J. F., \& Prince, S. (2002b). Estimation of tropical forest structural characteristics using large-footprint lidar. Remote Sensing of Environment, 79, 305-319.

Dubayah, R., Knox, R., Hofton, M., \& Blair, B. (2000). Land surface characterization using LiDAR remote sensing. In M. Hill, \& R. Aspinall (Eds.), Spatial information for land use management (pp. 25-38). Amsterdam: Gordon and Breach.

Dubayah, R. O., et al. (1997). The vegetation canopy LiDAR mission. Land Satellite information in the next decade II. Washington, D.C: American Society for Photgrammetry and Remote Sensing.

FAO (2006). Global forest resources assessment 2005. FAO Forestry Paper 147, Rome.

Fearnside, P. M. (1992). Forest biomass in Brazilian Amazonia: Comments on the estimate by Brown and Lugo. Interciencia, 17, 19-27.

Franklin, J. F., Perry, D. A., Schowalter, T. D., Harmon, M. E., McKee, A., \& Spies, T. A (1989). Importance of ecological diversity in maintaining long-term site 
productivity. In R. Meurisse, R. Thomas, J. Boyle, J. Means, C. R. Perry, \& R. F. Power (Eds.), Maintaining the long-term productivity of Pacific Northwest forest ecosystems. Portland: Timber Press.

Friedlingstein, P., Houghton, R. A., Marland, G., Hackler, J., Boden, T. A., Conway, T. J., et al. (2010). Update on $\mathrm{CO}_{2}$ emissions. Nature Geoscience, 3, 811-812.

Frolking, S., Palace, M. W., Clark, D. B., Chambers, J. Q., Shugart, H. H., \& Hurtt, G. C. (2009). Forest disturbance and recovery: A general review in the context of spaceborne remote sensing of impacts on aboveground biomass and canopy structure. J. Geophys. Res., 114(G00E02). doi:10.1029/2008JG000911 27 pp.

Goetz, S., Steinberg, D., Dubayah, R., \& Blair, B. (2007). Laser remote sensing of canopy habitat heterogeneity as a predictor of bird species richness in an eastern temperate forest, USA. Remote Sensing of Environment, 108(3), 254-263.

Goodale, C. L., Apps, M. J., Birdsey, R. A., et al. (2002). Forest carbon sinks in the northern hemisphere. Ecological Applications, 12, 891-899.

Green, R. M. (1998). Relationships between polarimetric SAR backscatter and forest canopy and sub-canopy biophysical properties. International Journal of Remote Sensing, 19, 2395-2412.

Gustafson, E. J. (1998). Quantifying landscape spatial pattern: What is the state of the art? Ecosystems, 1, 143-156.

Hajnsek, I., Kugler, F., Lee, S. K., \& Papathanassiou, K. P. (2009). Tropical forest parameter estimation by means of Pol-InSAR: The INDREX-II Campaign. IEEE Transactions on Geoscience and Remote Sensing.

Hall, F. G., Knapp, D. E., \& Huemmrich, K. F. (1997). Physically-based classification and satellite mapping of biophysical characteristics in the southern Boreal forest. BOREAS JGR Special Issue, 102(D24), 29,567-29,581.

Hartung, S. C., \& Brawn, J. D. (2005). Effects of savanna restoration on the foraging ecology of insectivorous songbirds. Condor, 107, 879-888.

Hartshorn, G. S. (1978). Tree falls and tropical forest dynamics. In P. B. Tomlinson, \& M. H. Zimmerson (Eds.), Tropical trees as living systems (pp. 617-638). Cambridge, UK: Cambridge University Press.

Houghton, R. A. (2003). Revised estimates of the annual net flux of carbon to the atmosphere from changes in land use and land management 1850-2000. Tellus, Ser. $B, 55,378-390$.

Houghton, R. A. (2005). Aboveground forest biomass and the global carbon balance Global Change Biology, 11, 945-958.

Houghton, R. A. (2008). Biomass. In S. E. Jorgensen, \& B. D. Fath (Eds.), Encyclopedia of Ecology (pp. 448-453). (1st Edition). Oxford: Elsevier.

Houghton, R. A., Butman, D., Bunn, A. G., Krankina, O. N., Schlesinger, P., \& Stone, T. A (2007). Mapping Russian forest biomass with data from satellites and forest inventories. Environmental Research Letters, 2, 045032. doi:10.1088/1748 9326/2/4/045032.

Houghton, R. A., \& Goetz, S. J. (2008). New satellites help quantify carbon sources and sinks. EOS Transactions, 89, 43.

Houghton, R. A., Lawrence, K. T., Hackler, J. L., \& Brown, S. (2001). The spatia distribution of forest biomass in the Brazilian Amazon: A comparison of estimates. Global Change Biology, 7, 731-746.

Houghton, R. A., Hall, F. G., \& Goetz, S. J. (2009). Importance of biomass in the global carbon cycle, Journal of Geophysical Research, Biogeosciences VOL. 114, G00E03. doi:10.1029/2009JG000935.

Hurtt, G. C., Dubayah, R., Drake, J., Moorcroft, P. R., Pacala, S. W., Blair, J. B., et al. (2004) Beyond potential vegetation: Combining LiDAR data and a height-structured model for carbon studies. Ecological Applications, 14, 873-883.

Hurtt, G. C., Fisk, J., Thomas, R. Q., Dubayah, R., Moorcroft, P. R., \& Shugart, H. H. (2010). Linking models and data on vegetation structure. J. Geophys. Res., 115(G00E10). doi:10.1029/2009JG000937.

Hurtt, G. C., Moorcroft, P. R., Pacala, S. W., \& Levin, S. A. (1998). Terrestrial models and global change: Challenges for the future. Global Change Biology, 4(5), 581-590.

Hurtt, G. C., Pacala, S. W., Moorcroft, P. R., Caspersen, J., Shevliakova, E., Houghton, R. et al. (2002). Projecting the future of the US carbon sink. Proceedings of the National Academy of Sciences of the United States (PNAS), 99(3), 1389-1394.

Hyde, P., Dubayah, R., Peterson, B., Blair, J. B., Hofton, M., Hunsaker, C., et al. (2005) Mapping forest structure for wildlife habitat analysis using waveform LiDAR: Validation of montane ecosystems. Remote Sensing of Environment, 96, 427-437.

Hyde, P., Dubayah, R., Walker, W., Blair, J. B., Hofton, M., \& Hunsaker, C. (2006). Mapping forest structure for wildlife habitat analysis using multi-sensor (LiDAR, SAR/InSAR, ETM+, Quickbird) synergy. Remote Sensing of Environment, 102(1-2), 63-73.

Imhoff, M. L., Sisk, T. D., Milne, G., Morgan, G., \& Orr, T. (1997). Remotely sensed indicators of habitat heterogeneity: Use of synthetic aperture Pol-SAR in mapping vegetation structure and bird habitat. Remote Sensing of Environment, 60, 217-227.

Ishii, H. T., Tanabe, S., \& Hiura, T. (2004). Exploring the relationships among canopy structure, stand productivity, and biodiversity of temperature forest ecosystems. Forest Science, 50(3), 342-355.

Iverson, L. R., Brown, S., Prasad, A., Mitasova, H., Gillespie, A. J. R., \& Lugo, E. E. (1994) Use of GIS for estimating potential and actual forest biomass for continental South and Southeast Asia. In V. H. Dale (Ed.), Effects of land use change on atmospheric $\mathrm{CO}_{2}$ concentrations: South and Southeast Asia as a case study (pp. 67-116). New York: Springer-Verlag.

Johnson, C. M., Vieira, I. C. G., Zarin, D. J., Frizano, J., \& Johnson, A. H. (2001). Carbon and nutrient storage in primary and secondary forests in eastern Amazonia. Forest Ecology and Management, 147, 245-252.

Jenkins, J. C., Chojnacky, D. C., Heath, L. S., \& Birdsey, R. A. (2003). National-scale biomass estimators for United States tree species. Forest Science, 49(1), 12-35.

Kasischke, E., Melack, J., \& Dobson, M. C. (1997). The use of imaging radars for ecological applications.
Knight, D. H. (1975). A phytosociological analysis of species-rich tropical forest on Barro Colorado Island. Panama. Ecol. Mon., 45, 259-284.

Kohler, P., \& Huth, A. (2010). Towards ground-truthing of spaceborne estimates of above-ground life biomass and leaf area index in tropical rain forests. Biogeosciences, 7, 2531-2543.

Le Quéré, C., Raupach, M. R., Canadell, J. G., \& Marland, G. (2009, November). Trends in the sources and sinks of carbon dioxide. Nature Geoscience, 17. doi:10.1038/ ngeo689.

Lee, T. M., \& Jetz, W. (2008). Future battlegrounds for conservation under global change. Proceedings of the Royal Society B-Biological Sciences., 275, 1261-1270.

Lefsky, M. A., Cohen, W. B., Acker, S. A., Parker, G. G., Spies, T. A., \& Harding, D. (1999a). Lidar remote sensing of the canopy structure and biophysical properties of Douglas-fir western hemlock forests. Remote Sensing of Environment, 70, 339-361.

Lefsky, M. A., Harding, D., Cohen, W. B., Parker, G., \& Shugart, H. H. (1999b). Surface lidar remote sensing of basal area and biomass in deciduous forests of eastern Maryland, USA. Remote Sensing of Environment, 67, 83-98.

Lefsky, et al. (2002). LiDAR remote sensing for ecosystem studies. Bioscience, 52(1), 19-30.

Liu, D., Sun, G., Guo, Z., Ranson, K. J., \& Du, Y. (2010). Three Dimensional coherence radar backscatter model and simulations of scattering phase center of forest canopies. IEEE Transactions on Geoscience and Remote Sensing, 48(1), 349-357.

Lombardo, P., \& Oliver, C. J. (2001). Maximum likelihood approach to the detection of changes between multitemporal SAR images. Radar, Sonar and Navigation, IEE Proceedings, 148(Issue. 4), 200-210.

Luckman, A. J., Frery, A. C., Yansee, C. C. F., \& Groom, G. B. (1997). Texture in airborne SAR imagery of tropical forest and its relationship to forest regeneration stage. Int. J. of Rem. Sens., 18, 1333-1349.

MacArthur, R. H., \& MacArthur, J. W. (1961). On bird species diversity. Ecology, 42(3), 594-598.

Macarthur, R., Recher, H., \& Cody, M. (1966). On the relation between habitat selection and species diversity. The American Naturalist, 100, 319-322.

Maleque, M. A., Maeto, K., \& Ishii, H. T. (2009). Arthropods as bioindicators of sustainable forest management, with a focus on plantation forests. Applied Entomology and Zoology, 44, 1-11.

Martinuzzi, S., Vierling, L., Gould, W., \& Vierling, K. (2009). Improving the characterization and mapping of wildlife habitats with lidar data: Measurement priorities for the inland Northwest, USA. Gap Analysis Bulletin, 16, 1-8.

Masek, Jeffrey G., Huang, Chengquan, Wolfe, Robert, Cohen, Warren, Hall, Forrest, Kutler, Jonathan, et al. (2008). North American forest disturbance mapped from a decadal Landsat record. Remote Sensing of Environment, 112(2008), 2914-2926. doi:10.1016/j.rse.2008.02.010.

Matlack, G. R., \& Litvaitis, J. A. (1999). Forest edges. In M. L. Hunter (Ed.), Maintaining biodiversity in forest ecosystems (pp. 210-233). Cambridge: Cambridge University Press.

Means, J. E., Acker, S. A., Harding, D. J., Blair, J. B., Lefsky, M. A., Cohen, W. B., et al. (1999). Use of large-footprint scanning airborne lidar to estimate forest stand characteristics in the western Cascades of Oregon. Remote Sensing of. Environment, 67, 298-308.

Millennium Ecosystem Assessment Synthesis, Report (2005). Ecosystems and human well-being: Synthesis Millennium Ecosystem Assessment, World Resources Institute. 9781597260404

Mitchard, E.T.A, S. Saatchi, P. Meir, I.H. Woodhouse, Feldpausch, T.T., S.L. Lewis, B. Sonke, and C. Rowland, (this issue). Measuring Biomass Changes due to Woody Encroachment and Deforestation in the Forest-savanna Boundary Region of Central Africa using Multi-temporal L-band Radar Backscatter, Rem. Sens. Env.

Moorcroft, P. R., Hurtt, G., \& Pacala, S. (2001). A method for scaling vegetation dynamics: The ecosystem demography model (ED). Ecological Monographs, 71, 557-585.

Morgan, K., \& Freedman, B. (1986). Breeding bird communities in a hardwood forest succession in Nova Scotia. The Canadian Field-Naturalist, 100, 506-519.

Myneni, R. B., Dong, J. R., Tucker, C. J., Kaufmann, R. K., Kauppi, P. E., Liski, J., et al. (2001). A large carbon sink in the woody biomass of northern forests. Proceedings of the National Academy of Sciences, 98, 14784-14789.

Neef, T., Dutra, L. V., dos Santos, J. R., Freitas, C. C., \& Araujo, L. S. (2005). Tropical forest measurement by interferometric height modeling and P-band radar backscatter. Forest Science, 51(6), 585-594.

Nelson, R., Keller, C., \& Ratnaswamy, M. (2005). Locating and estimating the extent of Delmarva fox squirrel habitat using an airborne LiDAR profiler. Remote Sensing of Environ, ent, 96(3-4), 292-301.

Nilsson, M. (1996). Estimation of tree heights and stand volume using an airborne lidar system. Remote Sensing of Environment, 56, 1-7.

Oliver, C. D. (1980). Forest development in North America following major disturbances. Forest Eco. and Mgt., 3, 153-168.

Olson, D. M., \& Dinerstein, E. (2002). The Global 200: Priority ecoregions for global conservation. Annals of the Missouri Botanical Garden, 89, 199-224.

Pacala, S. W., Hurtt, G. C., Baker, D., Peylin, P., Houghton, R. A., Birdsey, R. A., et al. (2001). Consistent land-and atmosphere-based U.S. carbon sink estimates. Science, 292, 22 June.

Pang Yong, M. Lefsky, G. Sun, J. Ranson, 2010. Impact of footprint diameter and off-nadir pointing on the precision of canopy height estimates from spaceborne lidar, this issue.

Papathanassiou, K. P., \& Cloude, S. R. (2001). Single-baseline polarimetric SAR interferometry. IEEE Transactions on Geoscience and Remote Sensing, 39, 2352-2363.

Pastor, J. (2005). Thoughts on the generation and importance of spatial heterogeneity in ecosystems and landscapes. In G. M. Lovett, C. G. Jones, M. G. Turner, \& K. C. 
Weathers (Eds.), Ecosystem function in heterogeneous landscapes (pp. 49-66). New York: Springer.

Peddle, D. R., Hall, F. G., \& LeDrew, E. F. (1999). Spectral mixture analysis and geometric optical reflectance modeling of boreal forest biophysical structure. Remote Sensing of Environment, 67(3), 288-297.

Peterson, G., Allen, C. R., \& Holling, C. S. (1998). Ecological resilience, biodiversity and scale. Ecosystems, 1, 6-18.

Pulliainen, J., Grandell, J., \& Hallikaninen, M. (1999). HUT snow emission model and its applicability to snow water equivalence retrieval. IEEE Trans. On Geosci. Rem. Sensing, 37, 1378-1390.

Ranson, K. J., Kovacs, K., Sun, G., \& Kharuk, V. I. (2003). Disturbance recognition in the boreal forest using radar and Landsat-7. Canadian Journal of Remote Sensing, 29, 271-285.

Ranson, K. J., \& Sun, G. (1997). An evaluation of AIRSAR and SIR-C/X-SAR images of northern forest attributes in Maine, USA. Remote Sensing of Environment, 59, 203-222.

Raup, H. M. (1964). Some problems in ecological theory and their relation to conservation. Journal of Ecology, 52, 19-28 Suppl.

Reinkensmeyer, D. P., Miller, R. F., Anthony, R. G., \& Marr, V. E. (2007a). Avian community structure along a mountain big sagebrush successional gradient. J. Wildlife Manag., 71(4), 1057.

Reinkensmeyer, D. P., Miller, R. F., Anthony, R. G., \& Marr, V. E. (2007b). Avian community structure along a mountain big sagebrush successional gradient. Journal of Wildlife Management, 71, 1057-1066.

Richards, J. A., Sun, G., \& Simonett, D. S. (1987). L-band radar backscatter modeling of forest stands. IEEE Transactions on Geoscience and Remote Sensing, GE-25(No. 4), 487-498.

Rignot, E. J. M., \& Van Zyl, J. J. (1993). Change detection techniques for ERS-1 SAR data. IEEE Transactions on Geoscience and Remote Sensing, 31(4), 896-906.

Rignot, E., \& Thomas, R. H. (2002, August 30). Mass Balance of Polar Ice Sheets. Science, 297(5586), 1502.

Rignot, E., Way, J., Williams, C., \& Viereck, L. (1994, Sept.t). Radar estimates of above ground biomass in boreal forests of interior Alaska. IEEE Trans. Geosci. Remote Sensing, 32, 1117-1124.

Rodenbeck, C., Houweling, S., Gloor, M., \& Heimann, M. (2003). CO2 flux history (19822001 ) inferred from atmospheric data using a global inversion of atmospheric transport. Atmos. Chem. Phys., 3, 1919-1964.

Rosenqvist, A., Milne, A., Lucas, R., Imhoff, M., \& Dobson, C. (2003). A review of remote sensing technology in support of the Kyoto Protocol. Environmental Science and Policy, 6, 441-455.

Rowland, C., Balzter, H., Dawson, T., Luckman, A., Skinner, L., \& Patenaude, G. (2002). Biomass estimation of Thetford forest from SAR data: Potential and limitations. ForestSAT, Edinburgh, Forest Research, Forestry Commission, CD-ROM.

Saatchi, S., Despain, D., Halligan, K., Crabtree, R., \& Yu, Y. (2007a). Estimating forest fire fuel load from radar remote sensing. IEEE Geoscience and Remote Sensing, 45, 1726.

Saatchi, S. S., Houghton, R. A., dos Santos Alvala, R. C., Soares, J. V., \& Yu, Y. (2007b). Distribution of aboveground live biomass in the Amazon basin. Global Change Biology, 13,816 .

Saatchi, S., \& Moghaddam, M. (2000). Estimation of crowns and stem water content and biomass of boreal forest using polarimetric SAR imagery. IEEE Trans. Geosci. Rem Sens., 38, 697-709.

Saatchi, S., Soares, J. V., \& Alves, D. S. (1997). Mapping deforestation and land cover in Amazon rainforest using SIR-C imagery. Remote Sensing of Environment., 59(2), 191-202.

Saatchi, S., M. Marlier, R. Chazdon, D. Clark and Ann Russell, (this issue). Impacts of spatial variability of forest structure on radar estimation of of aboveground biomass in tropical forests. Rem Sens of Environ.

Sala, O. E., Chapin, F. S., Armesto, J. J., Berlow, E., Bloomfield, J., Dirzo, R., et al. (2000). Biodiversity-Global biodiversity scenarios for the year 2100. Science, 287. 1770-1774.

Salas, W. A., Ducey, M. J., Rignot, E., \& Skole, D. (2002). Assessment of JERS-1 SAR for monitoring secondary vegetation in Amazonia: I. Spatial and temporal variability in back scatter across a chrono-sequence of secondary vegetation stands in Rondonia. International Journal of Remote Sensing, 23, 1357-1379.

Saugier, B., Roy, J., \& Mooney, H. A. (2001). Estimations of global terrestrial productivity: Converging toward a single number? In J. Roy, B. Saugier, \& H. A Mooney (Eds.), Terrestrial global productivity (pp.543-557). San Diego, California: Academic Press.

Shugart, H. H., Bourgeau-Chavez, L. L., \& Kasischke, E. S. (2000). Determination of stand properties in boreal and temperate forests using high-resolution photography and satellite imagery. Forest Science, 46, 478-486.

Siegert, F., Ruecker, G., Hinrichs, A., \& Hoffmann, A. A. (2001). Increased damage in logged fires during droughts caused by El Nino. Nature, 414, 437-440.

Soenen, S. A., Peddle, D. R., Coburn, C. A., Hall, R. J., \& Hall, F. G. (2009). Canopy reflectance model inversion in multiple forward mode: Forest structural information retrieval from solution set distribution. Photogrammetric Engineering \& Remote Sensing, 75(4), 361-374.

Spies, T. A., \& Turner, M. G. (1999). Dynamic forest mosaics. In M. Hunter (Ed.), Maintaining biodiversity in forest ecosystems (pp. 95-160). Cambridge University Press: Cambridge.

Stern Review on the economics of climate change (2008). Science marketing, freepost. The Edinburgh Building, Cambridge: Cambridge University Press CB2. http://www. cambridge.org/9780521700801

Sun, G., \& Ranson, K. J. (1995). A three-dimensional radar backscatter model of forest canopies. IEEE Trans. Geosci. Remote Sens., 33, 372-382.

Sun, G., Simonett, D. S., \& Strahler, A. H. (1991). A radar backscatter model for discontinuous coniferous forests. IEEE Transaction on Geoscience and Remote Sensing, Vol. GE.
Ter-Mikaelian, M. T., \& Korzukhin, M. D. (1997). Biomass equations for sixty-five North American tree species. Forest Ecology and Management, 97, 1-24.

Tews, J., Brose, U., Grimm, V., Tielborger, K., Wichmann, M., Schwager, M., et al. (2004) Animal species diversity driven by habitat heterogeneity/diversity: the importance of keystone structures. Journal of Biogeography, 31, 79-92.

Thomas, R. Q., Hurtt, G., Dubayah, R., Ranson, J., Ollinger, S., \& Aber, J. (2006). The importance of heterogeneity: Integrating LiDAR remote sensing and height structured ecosystem models to improve estimation of forest structure and dynamics. AGU Fall Meeting, San Francisco.

Thomas, R. Q., Hurtt, G. C., Dubayah, R., \& Schilz, M. (2008). Using lidar data and a height structured ecosystem model to estimate forest carbon stocks and fluxes over mountainous terrain. Canadian Journal of Remote Sensing, 34(2), S351-S363.

Thomas, R. Q., Hurtt, G. C., Dubayah, R., \& Schilz, M. (2008). Using lidar data and a height structured ecosystem model to estimate forest carbon stocks and fluxes over mountainous terrain. Can. J. Rem. Sens., 34, S351-S363.

Treuhaft, R. N., Madsen, S. N., Moghaddam, M., \& Van Zyl,J.J. (1996). Vegetation characteristics and surface topography from interferometric radar. Radio Science, 31, 1449-1485.

Treuhaft, R. N., \& Siqueira, P. R. (2000). Vertical structure of vegetated land surfaces from interferometric and polarimetric radar. Radio Science, 35, 141-177.

Tucker, C. J., \& Townshend, J. R. G. (2000). Strategies for monitoring tropica deforestation using satellite data. Int. J. Remote Sensing, 21 (no. 6 \& 7), 1461-1471

UNFCCC LCA draft agreement on REDD, FCCC/AWGLCA/2009/L.7/Add.6. (2009, December 15).

Verner, J., Morrison, M. L., \& Ralph, C. J. (Eds.). (1986). Modeling habitat relationships of terrestrial vertebrates. Madison, Wisconsin: The University of Wisconsin Press.

Weise, David R., \& Biging, Gregory S. (1997). A qualitative comparison of fire spread models incorporating wind and slope effects, qualitative comparison of fire spread models incorporating wind and slope effects. Forest Science, 43(2).

Weishampel, J. F., Urban, D. L., Shugart, H. H., \& Smith, J. B. (1992). Semivariograms from a forest transect gap model compared with remotely sensed data. Journal of Vegetation Science, 3, 521-526.

White, P. S. (1979). Pattern, process and natural disturbance in vegetation. Bot. Rev., 45 , 229-299.

Whitmore, T. C. (1974). Change with time and role of cyclones in tropical rain forest on Kolomgangara, Solomon Islands. Commonw. For. Inst. Paper 146.

Widlowski, J. -L., Pinty, B., GOBRON, N., Verstraete, M. M., Diner, D. J., \& Davis, A. B (2007). Canopy structure parameters derived from multi-angular remote sensing data for terrestrial carbon studies. Climatic Change, Vol. 67(2-3), 403-415. doi:10.1007/s10584-004-3566-3.

Willson, M. F. (1974). Avian community organization and habitat structure. Ecology, 55, 1017-1029.

Wilson, K. A., McBride, M. F., Bode, M., \& Possingham, H. P. (2006). Prioritizing global conservation efforts. Nature, 440, 337-340.

World Wildlife Fund (2006). Living planet report. Switzerland: Gland.

Wright, D. H. (1983). Species-energy theory-An extension of species-area theory. Oikos, 41, 496-506.

\section{Further reading}

Committee on Earth Science and Applications from Space (2007). Earth science and applications from space: National imperatives for the next decade and beyond. National Academies Press ISBN-10: 0-309-10387-8 ISBN-13: 978-0-309-10387-9.

Dubayah, R., \& Drake, J. B. (2000). LiDAR remote sensing for forestry. Journal of Forestry, $98,44-46$.

Freemark, K. E., \& Merriam, H. G. (1986). Importance of area and habitat heterogeneity to bird assemblages in temperate forest fragments. Biological Conservation, 36, 115-141.

Johnson, C. M., Zarin, D. J., \& Johnson, A. H. (2000). Post-disturbance above ground biomass accumulation in global secondary forests. Ecology, 81, 1395-1401. doi:10.1890/0012 9658(2000) 081.

Lesak, A.A., Radeloff, V.C., Hawbaker, T.J., Gobakken, T. \& Contrucci. K. (this issue). Modeling forest songbird species richness using lidar-derived forest structure. Remote Sensing of Environment.

McElhinny, C., Gibbons, P., Brack, C., \& Bauhus, J. (2005). Forest and woodland stand structural complexity: Its definition and measurement. Forest Ecology and Management, 218, 1-24.

Mittelbach, G. G., Steiner, C. F., Scheiner, S. M., Gross, K. L., Reynolds, H. L., Waide, R. B., et al. (2001). What is the observed relationship between species richness and productivity? Ecology, 82, 2381-2396.

Petit*, J. R., Jouzel†, J., Raynaud*, D., Barkovł, N. I., Barnola*, J. -M., Basile*, I., et al. (1999). Climate and atmospheric history of the past 420,000 years from the Vostok ice core, Antarctica. Nature, 399, 429-436.

Probst, J. R., \& Weinrich, J. (1993). Relating Kirtlands Warbler population to changing landscape composition and structure. Landscape Ecology, 8(4), 257-271.

Rackham, O. (1992). Mixtures, mosaics and clones: The distribution of trees within European woods and forests. In M. G. R. Cannell, D. C. Malcolm, \& P. A. Robertson (Eds.), The ecology of mixed-species stands of trees (pp. 1-20). Oxford: Blackwell Scientific Publications.

Rignot, E., Box, J. E., Burgess, E., \& Hanna, E. (2008). Mass balance of the Greenland ice sheet from 1958 to 2007. Geophys. Res. Lett., 35, L20502. doi:10.1029/2008GL035417.

Scott, J. M., Tear, T. H., \& Davis, F. W. (1996). Gap analysis: A landscape approach to biodiversity planning. American Society for Photogrammetry and Remote Sensing, Bethesda, MD.

Smith, T. M., \& Huston, M. (1989). A theory of the spatial and temporal dynamics of plant communities. Vegetatio, 83, 49-69. 
Smith, T. M., \& Urban, D. L. (1988). Scale and the resolution of forest structural pattern. Vegetatio, 74, 143-150.

Solberg, S., Naesset, E., Hanssen, K. H., \& Christiansen, E. (2006). Mapping defoliation during a severe insect attack on Scots pine using airborne laser scanning. Remote Sensing of Environment, 102, 364-376.

Swain, M. D., \& Hall, J. B. (1988). The mosaic theory of forest regeneration and the determination of forest composition in Ghana. J. Tropical Ecology., 4, 253-269.

Thompson, D. B. A., \& Brown, A. (1992). Biodiversity in montane Britain - habitat variation, vegetation diversity and some objectives for conservation. Biodiversity and Conservation, 1, 179-208.

Trzcinski, M. K., Fahrig, L., \& Merriam, G. (1999). Independent effects of forest cover and fragmentation on the distribution of forest breeding birds. Ecological Applications, 9(2), 586-593.

Turner, W., Spector, S., Gardiner, N., Fladeland, M., Sterling, E., \& Steininger, M. (2003) Remote sensing for biodiversity science and conservation. Trends in Ecology and Evolution, 18, 306-314.
Vierling, K. T., Vierling, L. A., Gould, W. A., Martinuzzi, S., \& Clawges, R. M. (2008). Lidar: Shedding new light on habitat characterization and modeling. Frontiers in Ecology and the Environment, 6, 90-98.

Weishampel, J. F., Drake, J., Cooper, A., Blair, J., \& Hofton, M. (2007). Forest canopy recovery from the 1938 hurricane and subsequent salvage damage measured with airborne LiDAR. Rem. Sens. Environ., 109(2), 142-153.

Whitmore, T. C. (1982). On pattern and process in forests. In E. I. Newman (Ed.), The plant community as a working mechanism (pp. 45-59). Oxford: Blackwell Scientific Publ Special Publ. No. 1, British Ecological Society.

Williams, M., Ryan, C. M., Lewis, S. L., Feldpausch, T. R., \& Meir, P. (2009). Using satellite radar backscatter to predict above-ground woody biomass: A consistent relationship across four different African landscapes. Geophys. Res. Ltrs, 36, L23401. doi:10.1029/2009GL040692. 